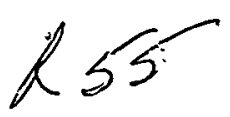

FINAL REPORT

\title{
MELTING, SOLIDIFICATION, REMELTING, AND SEPARATION OF GLASS AND METAL
}

Principal Investigator:

M. A. Ebadian, Ph.D.

Florida International University

Collaborators:

Y. Z. Liu,

R. C. Xin,

and K. K. Sundaram

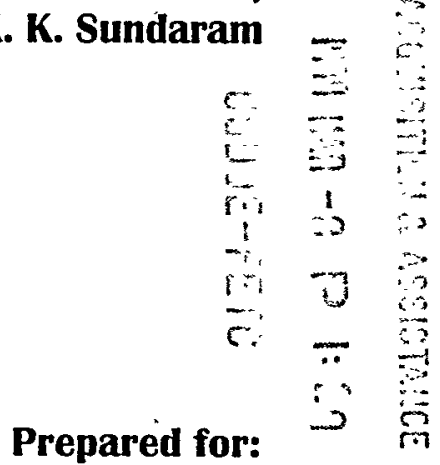

U.S. Department of Energy

Office of Environmental Management Office of Science and Technology

Hemispheric Center for Enuironmental Technology (HCET)

Florida International University, Center for Engineering \& Applied Sciences

10555 West Flagler Street, EAS-2100, Miami, Florida 33174

305-348-4238 • FAX: (305) 348-1852 - World Wide Web Site: http://www.hcet.fiu.edu

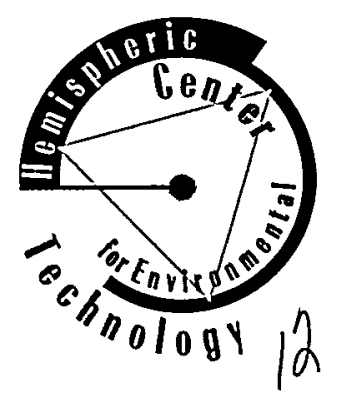




\section{DISCLAIMER}

This report was prepared as an account of work sponsored by an agency of the United States government. Neither the United States government nor any agency thereof, nor any of their employees, nor any of its contractors, subcontractors, nor their employees makes any warranty, express or implied, or assumes any legal liability or responsibility for the accuracy, completeness, or usefulness of any information, apparatus, product, or process disclosed, or represents that its use would not infringe upon privately owned rights. Reference herein to any specific commercial product, process, or service by trade name, trademark, manufacturer, or otherwise does not necessarily constitute or imply its endorsement, recommendations, or favoring by the United States government or any agency thereof. The views and opinions of authors expressed herein do not necessarily state or reflect those of the United States government or any agency thereof. 


\section{DISCLAIMER}

\section{Portions of this document may be illegible in electronic image products. Images are produced from the best available original document.}


Melting, Solidification, Remelting, and Separation of Glass and Metal

\section{Principal Investigator}

M.A. Ebadian, Ph.D.

Hemispheric Center for Environmental Technology

Florida International University

Miami, FL 33174

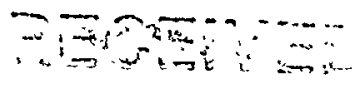

SAE 05239

(6)

\section{Florida International University \\ Collaborators}

Y.Z. Liu, R.C. Xin, and K. K. Sundaram

Hemispheric Center for Environmental Technology

Florida International University

Miami, FL 33174

November 1998

Prepared for

U.S. Department of Energy

Office of Environmental Management

Office of Science and Technology

Under Grant No. DE-FG-21-95EW55094 


\section{TABLE OF CONTENTS}

LIST OF FIGURES ii

LIST OF TABLES iv

1.0 INTRODUCTION 1

1.1 PROJECT OBJECTIVES 1

1.2 SUMMARY OF FY96 AND FY97 ACCOMPLISHMENTS ........................................... 1

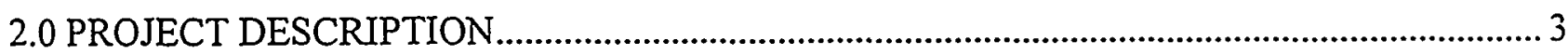

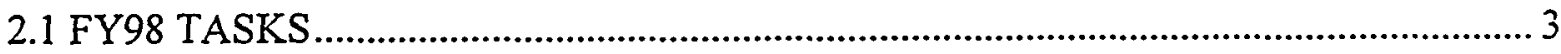

2.2 PROPOSED FUTURE TASKS...................................................................................

3.0 MELTING AND SOLIDIFICATION TEST RESULTS ……................................................... 5

3.1 EXPERIMENTAL AND MEASUREMENT SYSTEM ……............................................ 5

3.2 MELTING AND SOLIDIFICATION OF STAINLESS STEEL AND

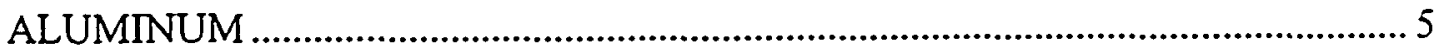

3.3 MELTING AND SOLIDIFICATION OF GLASSES ...................................................... 8

4.0 SIMULATION TESTS OF LIQUID-LIQUID SEPARATION .............................................. 10

5.0 NUMERICAL MODELING OF METAL/GLASS PHASE SEPARATION …........................... 15

5.1 MATHEMATICAL MODEL AND NUMERICAL METHODS ................................... 15

5.2 PHASE DISTRIBUTION RESULTS......................................................................... 16

6.0 MOLTEN METAL/GLASS PHASE SEPARATION EXPERIMENTS …................................ 17

6.1 MOLTEN METAL/GLASS PHASE SEPARATION TESTS ......................................... 17

6.2 STRUCTURE AND COMPOSITION ANALYSIS ......................................................... 20

7.0 CONTINUOUS SEPARATION DEMONSTRATION ............................................................... 24

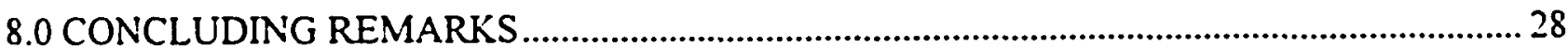

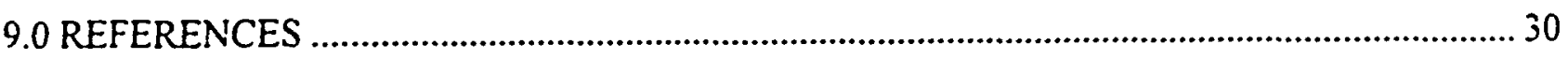




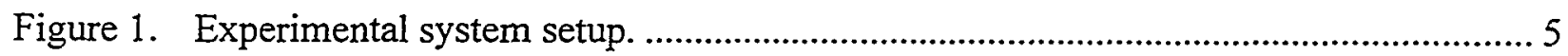

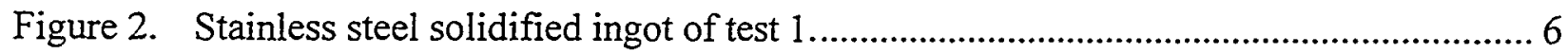

Figure 3. Temperature history of the solidification process of stainless steel in test 1...............6 6

Figure 4. Temperature curves for different locations in the stainless steel

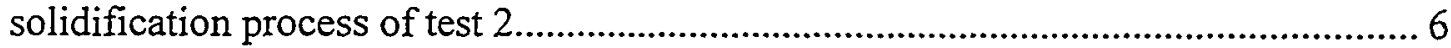

Figure 5. Aluminum induction melting temperature history................................................. 7

Figure 6. Aluminum solidification temperature curves for a hot crucible-central line ............. 7

Figure 7. Aluminum solidification température curves for a cool crucible-central line............. 8

Figure 8. Temperature history curves of SRS glass melting....................................................... 8

Figure 9. Temperature history curve of SRS glass solidification..............................................

Figure 10. The turntable and demonstration setup with kerosene-water stationary.................... 11

Figure 11. The interface shape of the kerosene-water system with a rotation

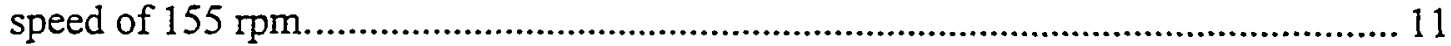

Figure 12. The interface shape of the kerosene-water system with a rotation

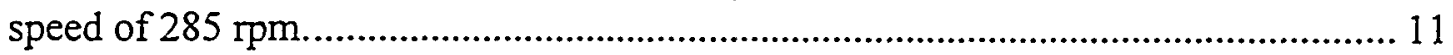

Figure 13. Separation efficiency of CS separation simulation tests........................................... 12

Figure 14. DCS simulation test setup and interface shapes. ....................................................... 13

Figure 15. The suspension of kerosene in PLUMR. ....................................................... 13

Figure 16. The mid-stage of the suspension separation (stopped at ten minutes)...................... 13

Figure 17. The mid-stage of the suspension separation (in rotating state at $300 \mathrm{rpm}$ )................. 14

Figure 18. The final phase distribution of the suspension after rotation................................... 14

Figure 19. Glass volume fraction distribution for the cases of $2 \%$ (left) and 5\% (right) glass content with a rotating speed of $300 \mathrm{rpm} . \ldots \ldots \ldots \ldots \ldots \ldots . . .16$

Figure 20. Glass volume fraction distribution for the case of $10 \%$ glass content with rotating speeds of $150 \mathrm{rpm}$ (left) and $300 \mathrm{rpm}$ (right) ......................... 16

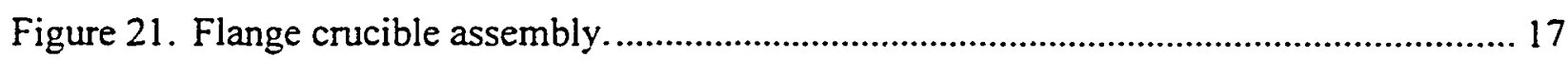

Figure 22. Molten metal/glass phase separation test setup. …………........................................ 17

Figure 23. Temperature curves for two different locations during the stainless steel and mixed glass solidification test. .................................................... 18

Figure 24. Final phase states after melting, rotating and solidification. ..................................... 19 
Figure 25. Metal phase ingot and the interface shape (150 rpm) .......................................... 19

Figure 26. Free surface and interface shape. .................................................................... 19

Figure 27. Samples from the ingot in static solidification. ..................................................... 20

Figure 28. Samples from the ingot in rotating solidification. ................................................. 20

Figure 29. SEM analysis of the samples from the ingot in static

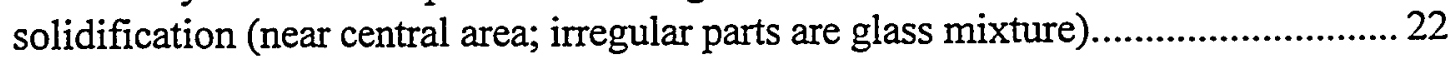

Figure 30. SEM analysis of the samples from the ingot in rotating solidification (Upper: near central area; Lower: near middle area; black points are contamination from outside)........................................................ 23

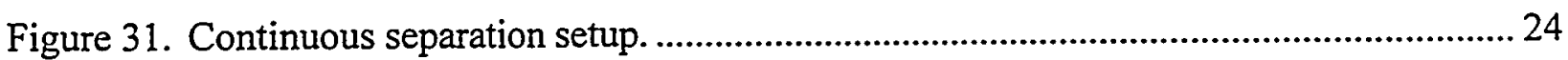

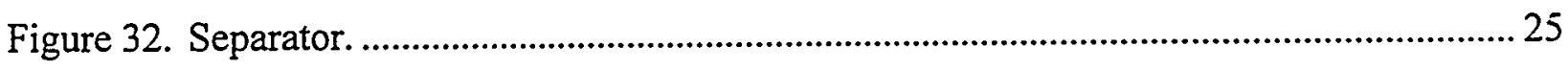

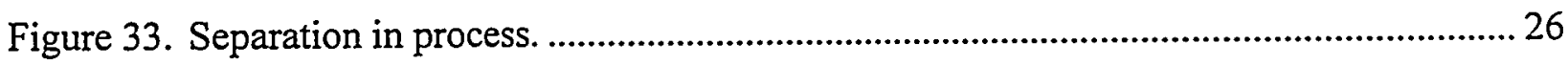

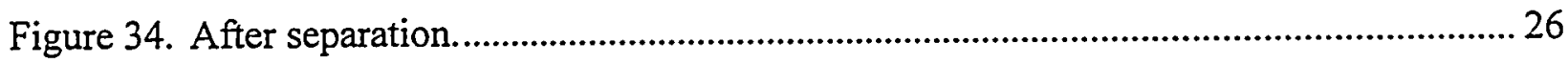




\section{LIST OF TABLES}

Table 1. The properties of the simulated liquids................................................................. 10

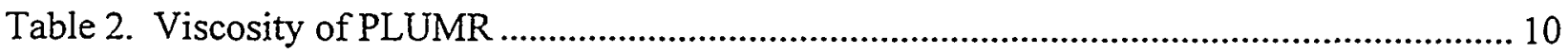




\subsection{INTRODUCTION}

Several kinds of mixed waste exist at various U.S. Department of Energy (DOE) sites. Vitrification is a particularly attractive technique for treating these wastes. Several hightemperature vitrification technologies have been developed for the treatment of a wide range of mixed waste types in both the low-level waste and transuranic (TRU) mixed waste categories currently in storage at DOE sites throughout the nation. These processes include the plasma hearth process, which is being developed by Science Applications International Corporation (SAIC), and the arc melter vitrification process, which is being developed at Idaho National Engineering and Environmental Laboratory (INEEL). The products of these processes are an oxide slag phase and a reduced metal phase. The metal phase has the potential to be recycled within the DOE complex. Enhanced slag/metal separation methods are needed to support these processes. A separation method to obtain highly refined recycled metals is also needed for the radioactively contaminated scrap metal recycling processes. This research project, which began at Florida International University's Hemispheric Center for Environmental Technology (FIUHCET) in FY96, involves an experimental investigation of the melting, solidification, remelting, and separation of glass and metal and the development of an efficient separation technology. Two innovative separation technologies-differential centrifugal separation (DCS) and centrifugal separation (CS) - were proposed and conceptually designed in FY96. The melting, solidification, and phase separation tests were conducted in fiscal year 1997 (FY97). In fiscal year 1998 (FY98), the testing and analysis of the phase separation tests in batch crucibles was finished, the continuous simulation separation test setup was fabricated and demonstrated, and the furnace system was modified to demonstrate flow-out molten glass and metal separation in rotating crucibles. These technologies will be delivered to DOE to meet the high demand for the efficient separation of glass and metals and for liquid-liquid separation.

\subsection{PROJECT OBJECTIVES}

The ultimate goal of this project is to find an efficient way to separate the slag phase from the metal phase in the molten state. A basic knowledge of the thermal, transport, and metallurgical phenomena that occur in the melting and solidification of glass, metal, and their mixtures is the foundation of the development of the separation methods.

In association with this project, an innovative liquid-liquid extractor/separator will be developed to meet the separation needs for efficient extraction/separation devices for the various DOE liquid waste treatment processes.

\subsection{SUMMARY OF FY96 AND FY97 ACCOMPLISHMENTS}

This three-year project commenced in October 1995 (FY96). In the first two fiscal years, the following accomplishments were achieved: 
- A literature review and an assessment of the baseline glass and metal separation technologies were performed. The results indicated that the baseline technology yields a high percentage of glass in the metal phase, necessitating further separation.

- The main melting and solidification system setup was established. A number of melting and solidification tests were conducted.

- Temperature distribution, solidification patterns, and flow field in the molten metal pool were simulated numerically for the solidification processes of molten aluminum and iron steel.

- Initial designs of the laboratory-scale DCS and CS technologies were also completed. The principal demonstration separation units using simulants were constructed.

- An application for a patent for an innovative liquid-liquid separation technology was submitted and is pending.

- Melting and solidification experiments for metal, glass, and their mixtures were conducted.

- Initial simulation tests for the CS and DCS technologies were completed.

- Numerical modeling of molten metal/glass phase distributions in rotating crucibles was completed.

- Initial melting and solidification experiments on metal, glass, and metal/glass mixtures were conducted. 


\subsection{PROJECT DESCRIPTION}

The aim of this project is to investigate the melting and solidification characteristics of selected glasses, metals, and their mixtures and to develop new or improved technologies for glass/metal separation. The following are the primary goals of this project:

- Develop and implement measurement methods for metal and glass melting and solidification tests.

- Investigate the melting and solidification characteristics of glass, metals, and their mixtures.

- Perform simulation testing.

- Perform molten-state, high-temperature testing to demonstrate the new or improved technologies.

\subsection{FY98 TASKS}

The following tasks were scheduled for completion in FY98:

(1) Finish the phase separation tests of molten glass and metal in rotating batch crucibles.

(2) Conduct the composition and structure analysis of solidified metal/glass mixture.

(3) Fabricate the continuous simulation test setup and demonstrate the operating principle and performances of separation of molten metal/glass mixture.

(4) Improve the melting furnace system and conduct the flow-out molten glass and metal separation using centrifugal force, if possible.

The following objectives were achieved:

(1) The tests of the phase separation of molten glass and metal in rotating state have been finished.

(2) The composition, microstructure, and macrostructure analysis of the solidified ingots was conducted in SEM.

(3) The continuous simulation test setup has been fabricated and set up to demonstrate the operating principle and performances. The continuous simulation test was conducted using several kinds of simulants.

(4) The new crucibles and other accessories for flow-out separation demonstration were made.

\subsection{PROPOSED FUTURE TASKS}

There are two primary objectives for the future:

- Design and fabricate the prototype extractor/separator and perform a field test to provide field performance data. 
Based on the results of continuous experimental tests, a prototype separator will be designed and fabricated with the optimal separator internal shape. The design will include the structure design, material selection, the determination of separator internal shape, the sealing method, and the device and algorithm for flow control. Most of the fabrication can occur in the FIU-HCET machine shop.

- Implement the high temperature separation process of metal/glass at DOE site.

Based on the data obtained from separation experiments of molten metal/glass mixture and results of continuous liquid/liquid separation, design industry-scale separation facility and process and find collaborators to manufacture the facility and set up the equipment to do real separation of metal/glass mixture. 


\subsection{MELTING AND SOLIDIFICATION TEST RESULTS}

\subsection{EXPERIMENTAL AND MEASUREMENT SYSTEM}

The melting and solidification system, which includes a furnace, a computer-controlled data acquisition unit, a power unit, cooling units for the power supply, and an induction coil, is shown in Figure 1.

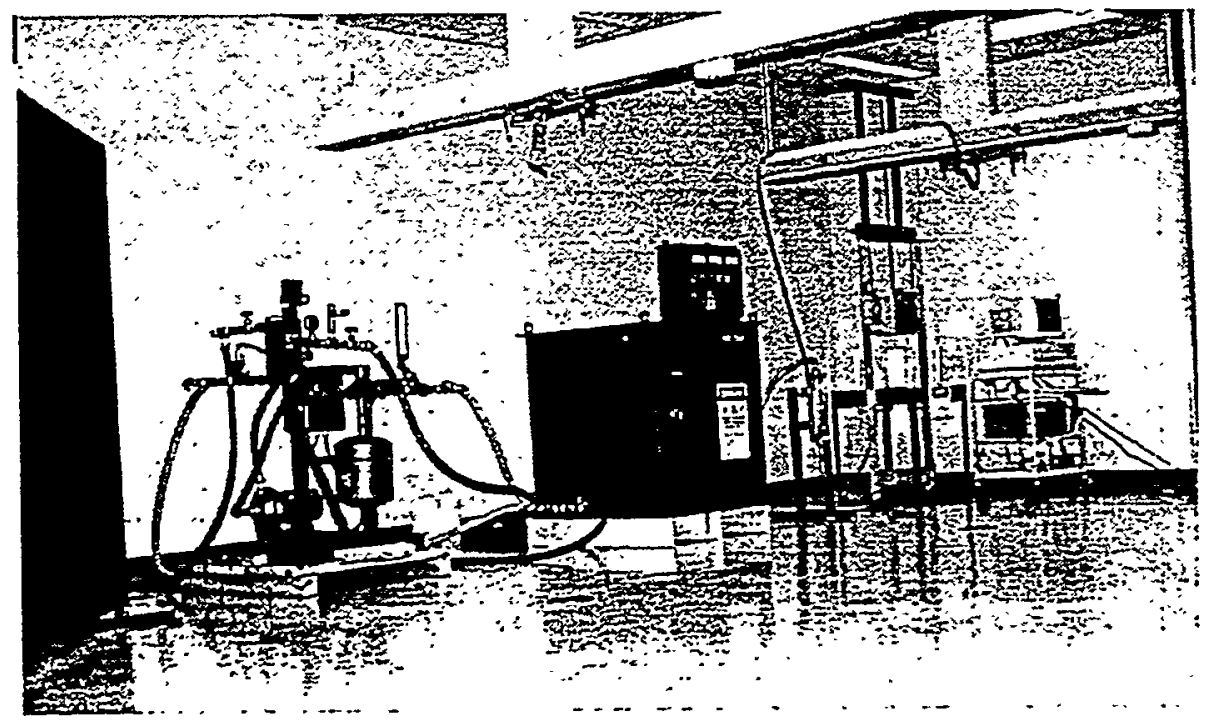

Figure 1. Experimental system setup.

In the solidification tests, the problem of how to measure the temperature of the molten stainless steel and aluminium during the solidification process has been solved. K-type and B-type thermocouples are used for temperature measurement in molten aluminum and stainless steel. respectively. A cast iron tube protects the K-type thermocouples. During measurement, a onetime-use quartz or ceramic thermocouple protection tube was used for B-type without thermocouple wire damage in the molten stainless steel solidification tests.

\subsection{MELTING AND SOLIDIFICATION OF STAINLESS STEEL AND ALUMINUM}

Several tests were conducted for solidification of stainless steel, some of which were unsuccessful because of problems with the crucible or thermocouple. Two successful tests were conducted using the improved temperature measurement technique. The solidified ingot and temperature history of one location inside the solidification region for the first test case are displayed in Figures 2 and 3. 
Thermocouple Location

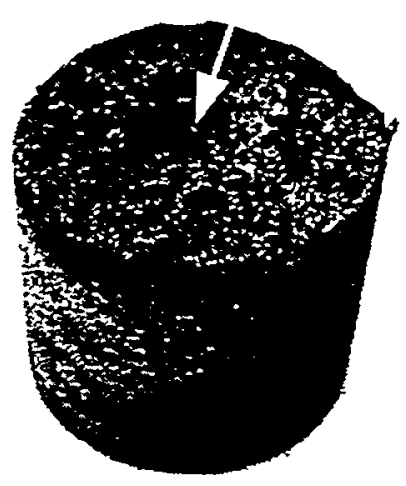

Figure 2. Stainless steel solidified ingot of test 1 .

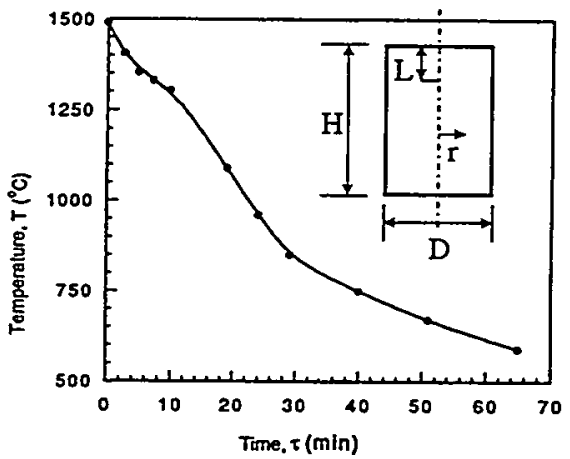

$H=6$ inch; $D=5$ inch; Location: $L=1.5$ inch; $r=0$

Figure 3. Temperature history of the solidification process of stainless steel in test 1.

In the second test case, temperatures of two different locations were measured, and the temperature curves are shown in Figure 4. Solidification occurred at the top first, then at the bottom, and the temperature curves are similarly shaped.

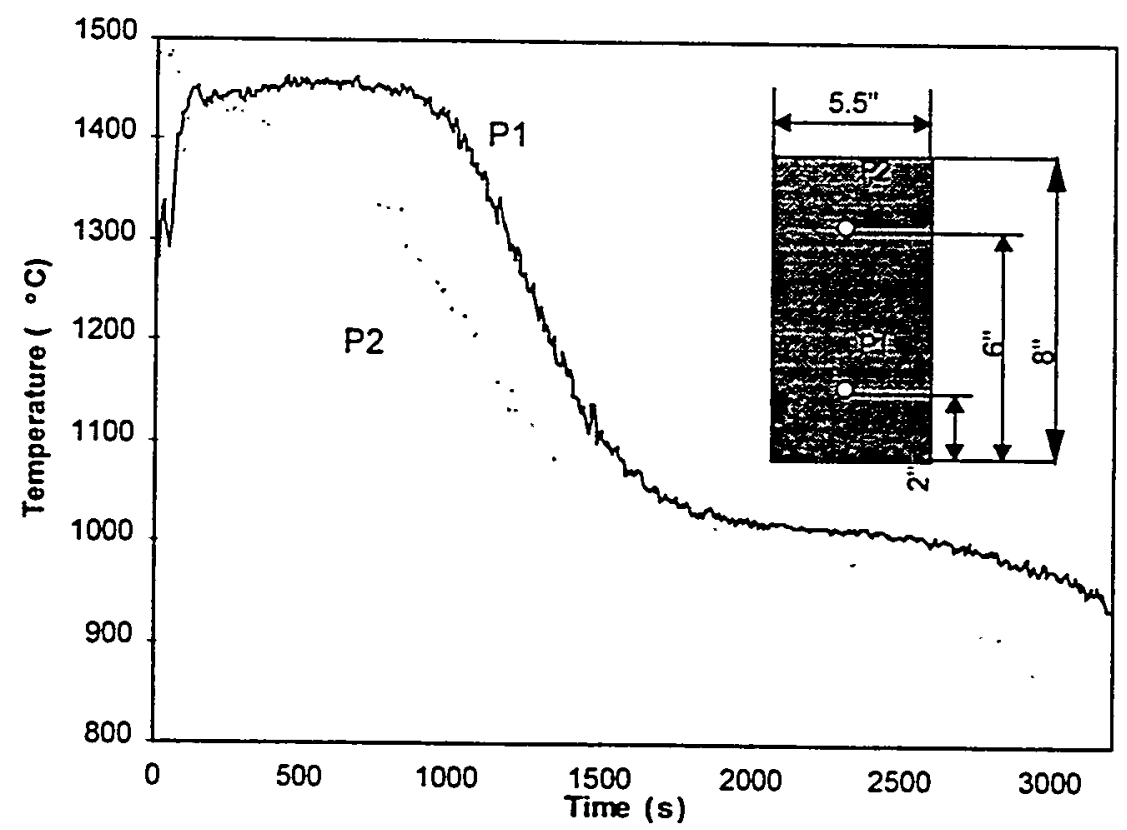

Figure 4. Temperature curves for different locations in the stainless steel solidification process of test 2. 
Aluminum melting/solidification tests have been conducted. The melting temperature history is shown in Figure 5.

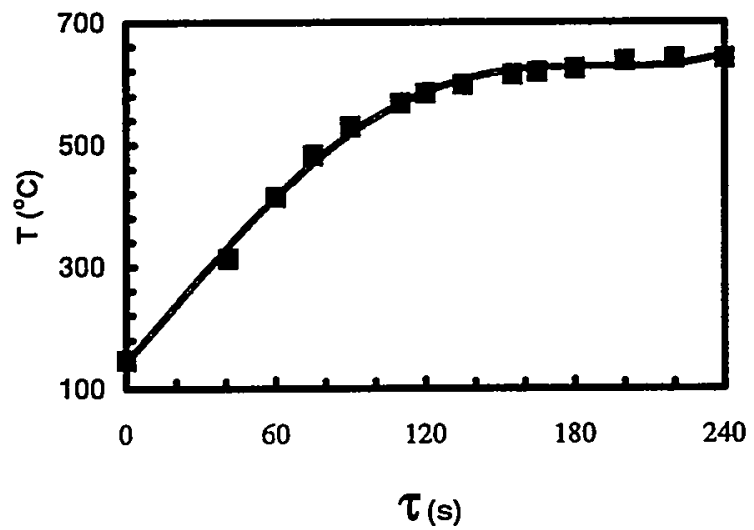

Figure 5. Aluminum induction melting temperature history.

The solidification temperature curves for two locations on the centerline in a hot crucible are displayed in Figure 6. The following can be observed from the figure: (1) the heating and melting rate is much faster than that of stainless steel melting; (2) the temperature is nearly uniform at different locations inside the solidified domain; (3) the convection, solidification, and conduction ranges can be observed.

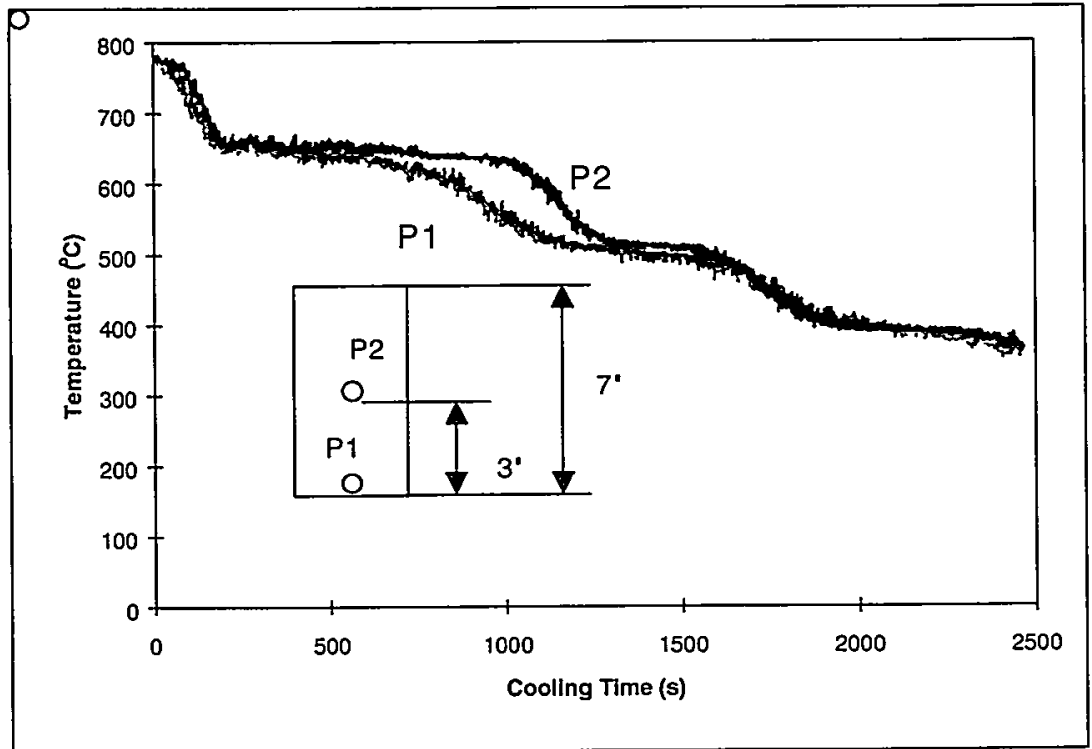

Figure 6. Aluminum solidification temperature curves for a hot crucible-central line. 
One additional aluminum solidification test in a cool crucible was conducted. Figures 7 shows the results of temperature measurement in the same position as Figure 6. It can be seen that the solidification rate is much faster in the cool crucible than in the hot crucible.

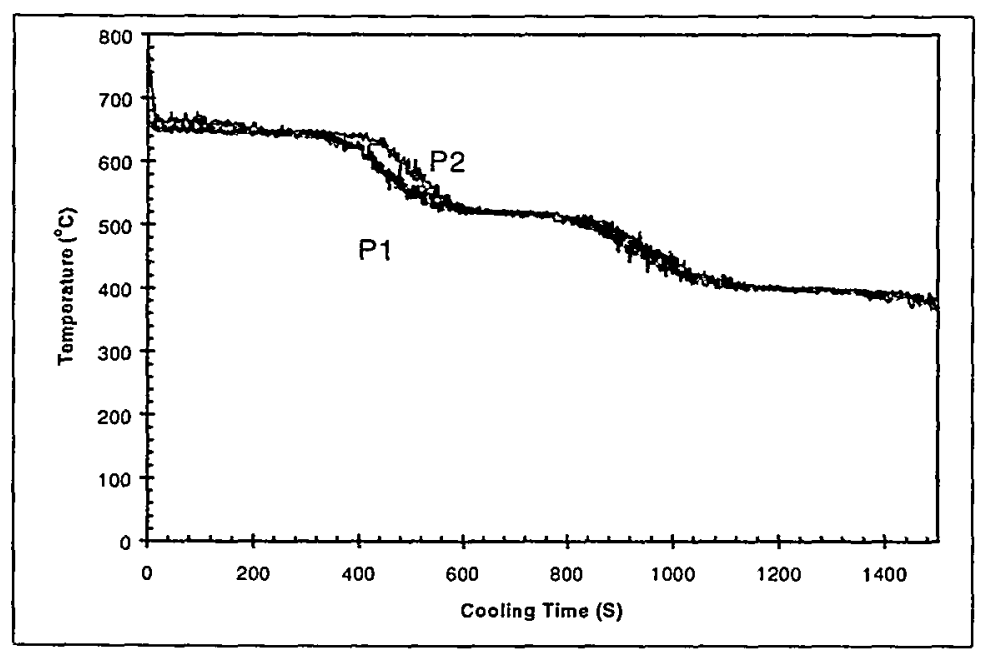

Figure 7. Aluminum solidification temperature curves for a cool crucible-central line.

\subsection{MELTING AND SOLIDIFICATION OF GLASSES}

Some melting and solidification tests of pure glass were conducted in a graphite crucible. The molten commercial borosilicate glass is too sticky for temperature measurement. In the test of Savannah River Site (SRS) glass, the glass was melted completely, and good flowability was observed. Temperature data were obtained and are displayed in Figures 8 and 9 for melting and solidification, respectively.

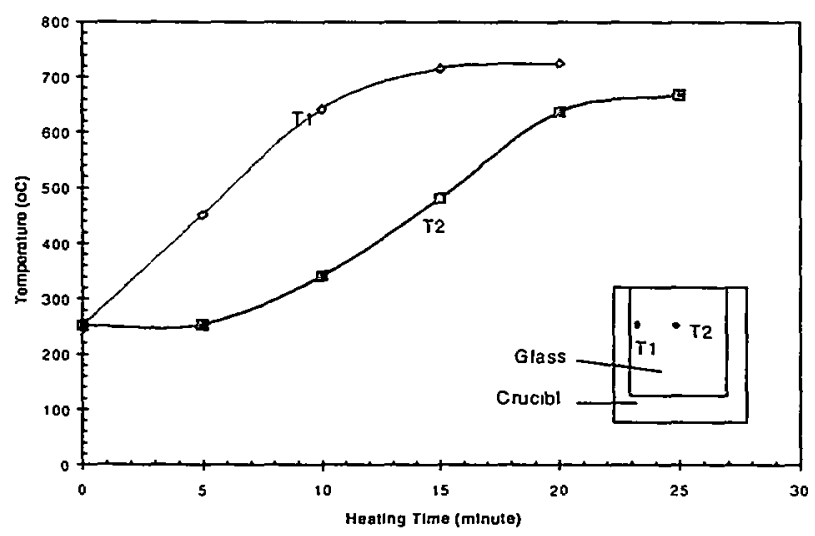

Figure 8. Temperature history curves of SRS glass melting. 


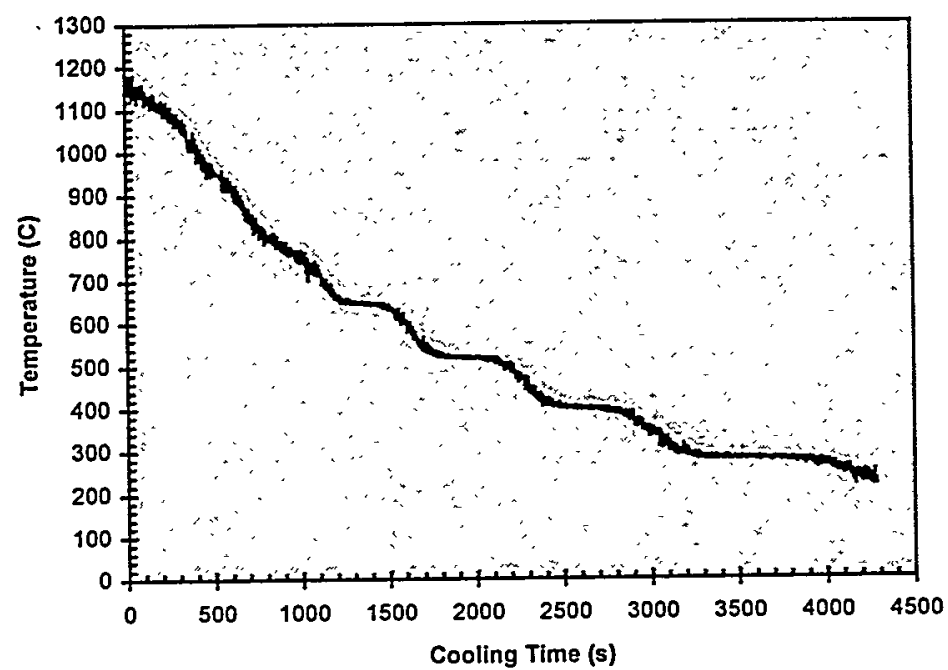

Figure 9. Temperature history curve of SRS glass solidification. 


\subsection{SIMULATION TESTS OF LIQUID-LIQUID SEPARATION}

The turntable and separator installation for the CS technology demonstration is shown in Figure 10 with the kerosene-water liquids stationary inside the separator. Simulation demonstrations of the CS separation process were conducted and videotaped for the following combinations of two immiscible liquids: water-PLUMR/water-methylene chloride and kerosene-water/kerosenePLUMR. The physical properties of the liquids used in the simulations were measured and are listed in Table 1.

Table 1.

The properties of the simulated liquids

\begin{tabular}{|l|c|c|c|c|c|c|}
\hline Properties & Water & PLUMR & $\begin{array}{c}\text { Methylene } \\
\text { chloride }\left(\mathrm{CH}_{2} \mathrm{Cl}_{2}\right)\end{array}$ & Sesame Oil & $\begin{array}{c}\text { Hexane } \\
\left(\mathrm{C}_{6} \mathrm{H}_{12}\right)\end{array}$ & Kerosene \\
\hline $\begin{array}{l}\text { Density } \\
\left(\mathrm{kg} / \mathrm{m}^{3}\right)\end{array}$ & 997.0 & 1306.0 & 1326.6 & 962.74 & 660.3 & 831.7 \\
\hline $\begin{array}{l}\text { Viscosity } \\
\mathrm{kg} /(\mathrm{m} \mathrm{s})\end{array}$ & $0.90275 \times 10^{-3}$ & $\begin{array}{c}\text { non-Newtonian } \\
0.114-0.646\end{array}$ & $<10^{-3}$ & 0.074 & $<10^{-3}$ & $<10^{-3}$ \\
\hline
\end{tabular}

The viscosity of the PLUMR liquid was measured using a Model RI-1-L viscometer manufactured by Rheology International Company. The measurement was conducted using the largest spindle and different rotation speeds. The data are listed in Table 2. It can be seen that PLUMR is a non-Newtonian liquid.

Table 2.

Viscosity of PLUMR

\begin{tabular}{|l|c|c|c|c|c|c|}
\hline Revolutions per minute & 6 & 10 & 12 & 20 & 30 & 50 \\
\hline Viscosity (cp) & $639.6-646$ & $402-425$ & $339-352$ & 234.5 & 169 & 114.5 \\
\hline
\end{tabular}

After the simulation test setup was established, the interface shape of two immiscible liquids under rotation was observed and photographed. Figures 11 and 12 show the interface shapes for the kerosene-water combination at rotating speeds of 155 and 285 revolutions per minute (rpm), respectively. The interface shape shows the geometric advantage of the CS separation; that is, the heavier liquid is pushed toward the outer corner of the separator where it flows out to the container for the heavier fluid. 


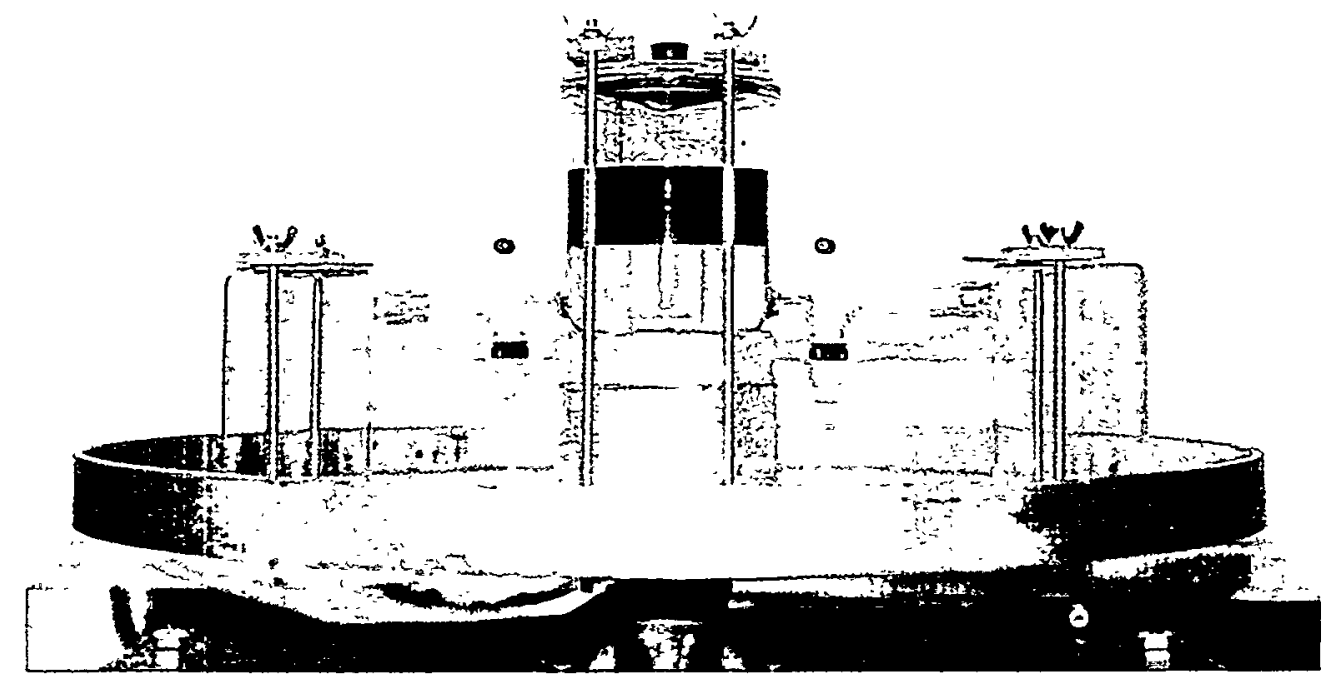

Figure 10. The turntable and demonstration setup with kerosene-water stationary.

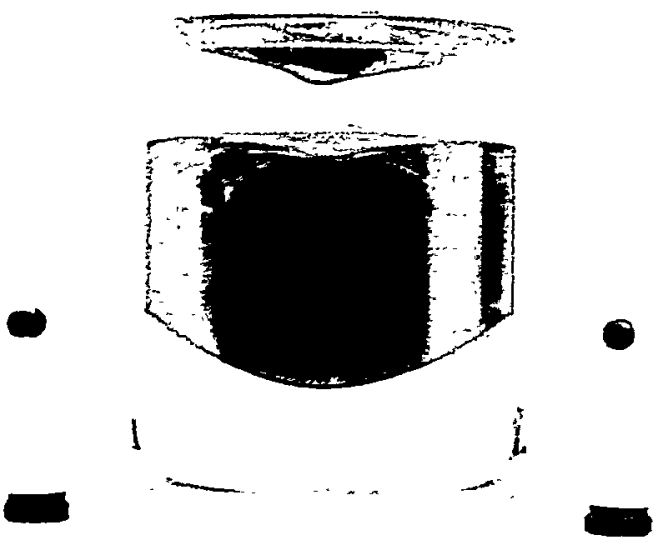

Figure 11. The interface shape of the kerosene-water system with a rotation speed of $155 \mathrm{rpm}$.

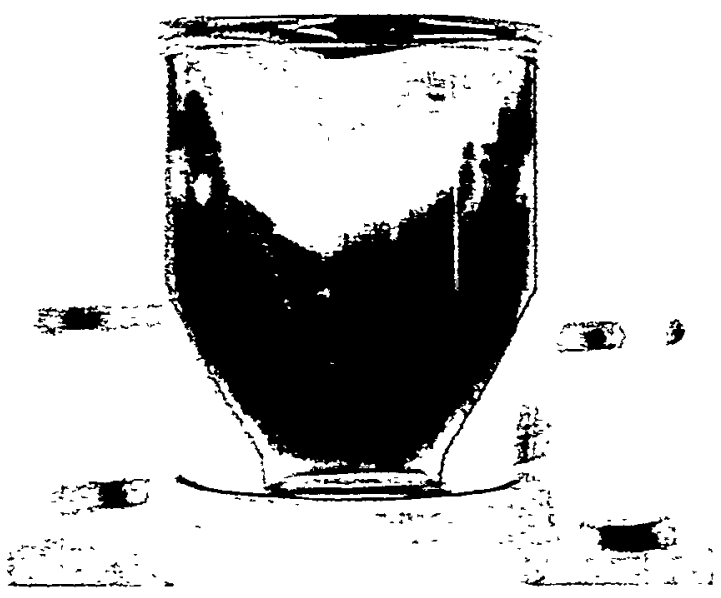

Figure 12. The interface shape of the kerosene-water system with a rotation speed of $285 \mathrm{rpm}$.

The separation efficiencies for different liquid combinations are measured and shown in Figure 13. The results indicate that separation efficiency increases with the rotating speed when it is lower than $300 \mathrm{rpm}$. 


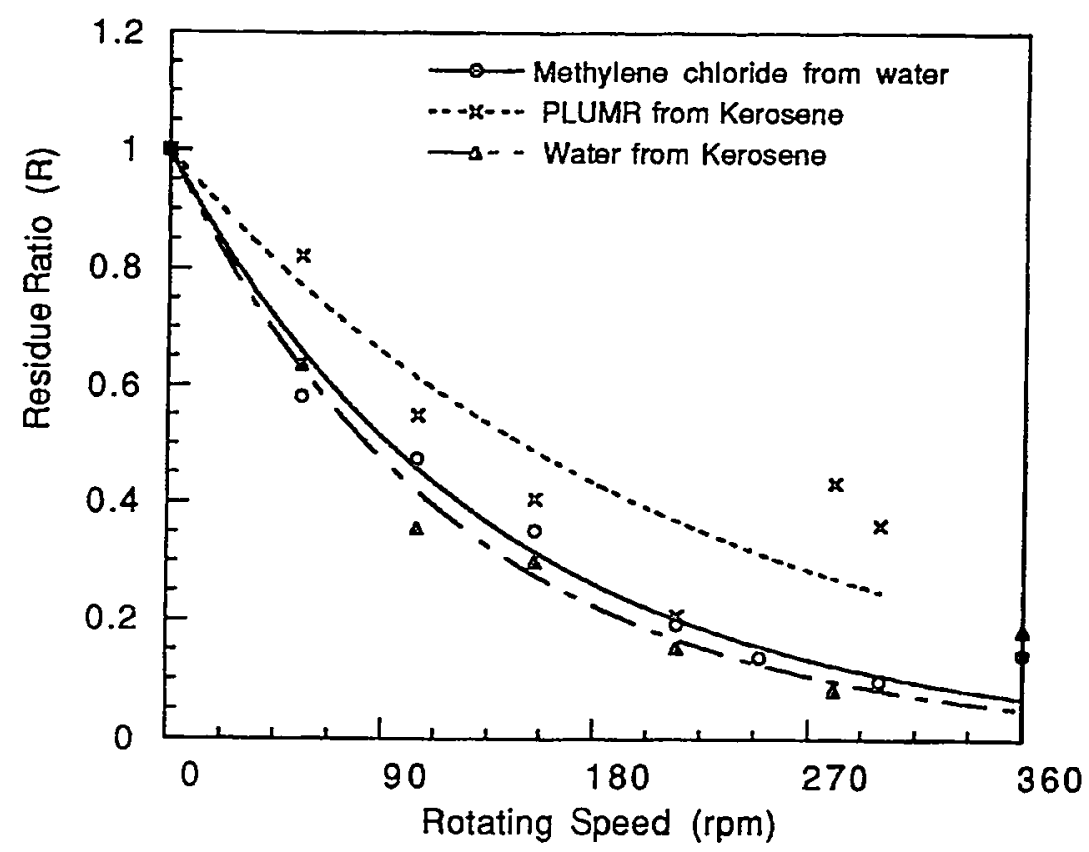

Figure 13. Separation efficiency of CS separation simulation tests.

The simulation tests for the DCS technology have been conducted. Figure 14 shows the setup and some interface shapes of two-immiscible liquids in the DCS separator.

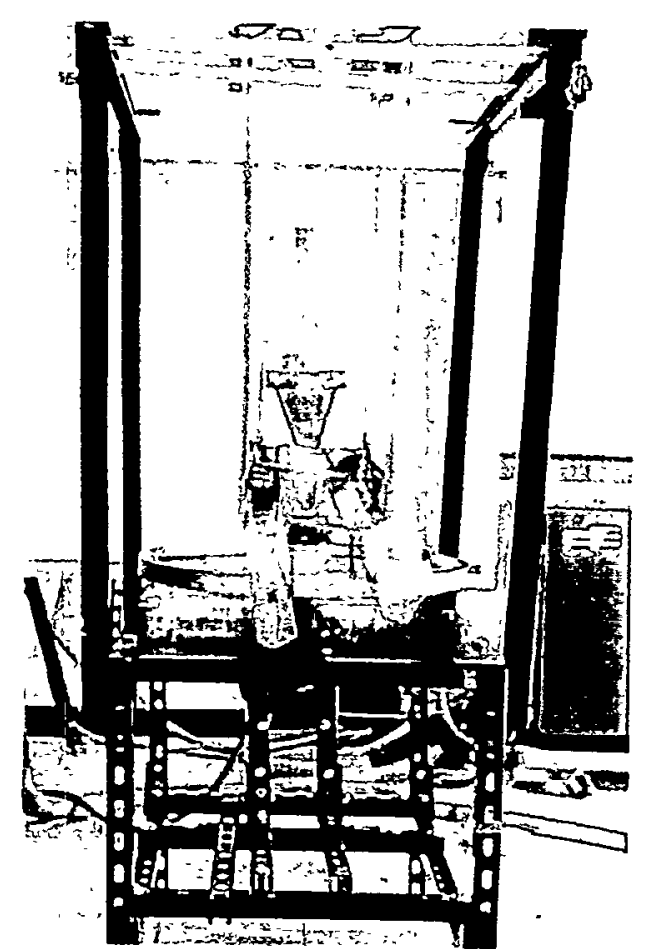

(a) Test setup

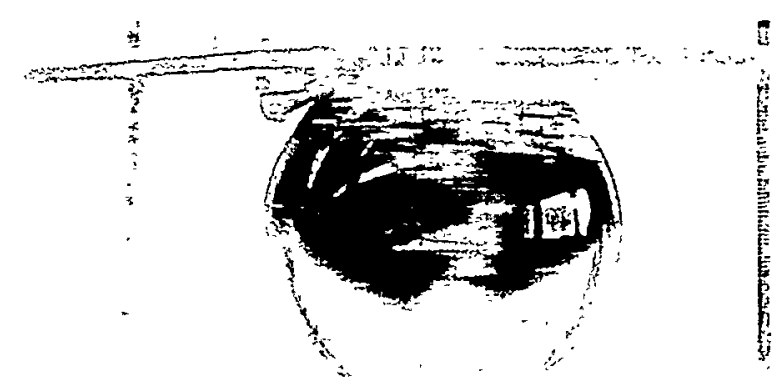

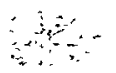

(b) Interface shape (155 rpm) 


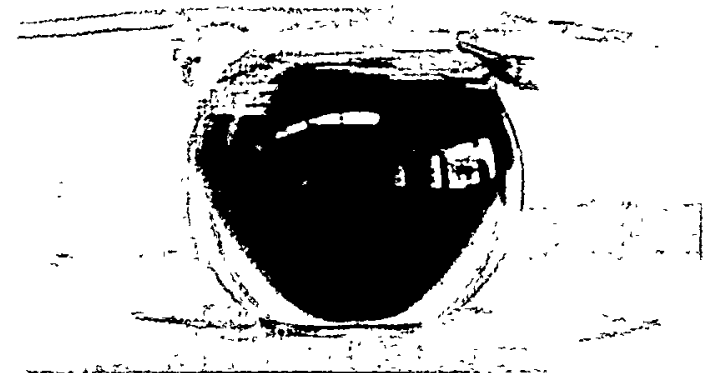

(c) Interface shape (237 rpm)

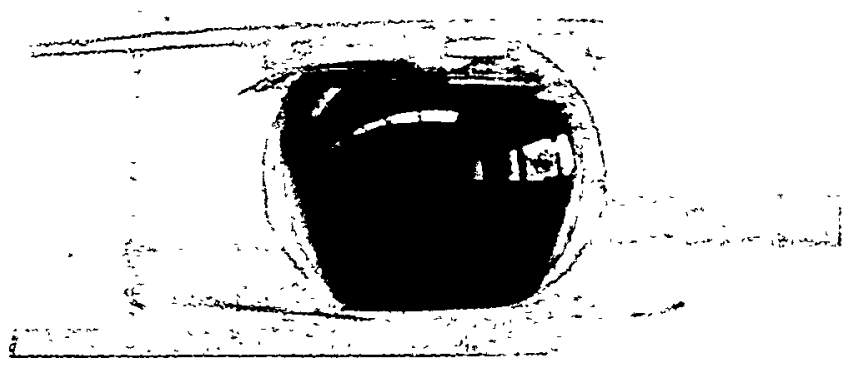

(d) Interface shape (285 rpm)

Figure 14. DCS simulation test setup and interface shapes.

Analysis of the DCS simulation test data indicates that separation efficiencies of $86 \%$ and $94.6 \%$ were obtained in the water-vegetable oil and PLUMR-oil separation tests, respectively.

One important test, the separation of a liquid-liquid suspension, was successfully demonstrated. Figures 15 through 18 show the separation process. During separation, three liquid layers existed: kerosene, a buffer layer (mixture), and the PLUMR layer, as seen in Figure 16. This demonstration verified the fact that centrifugal separation separates the glass inclusions in the molten metal phase.

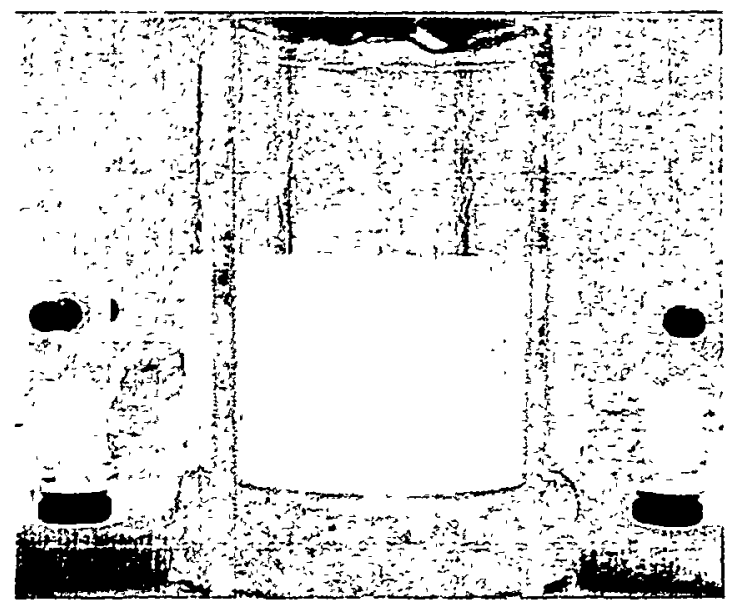

Figure 15. The suspension of kerosene in PLUMR.

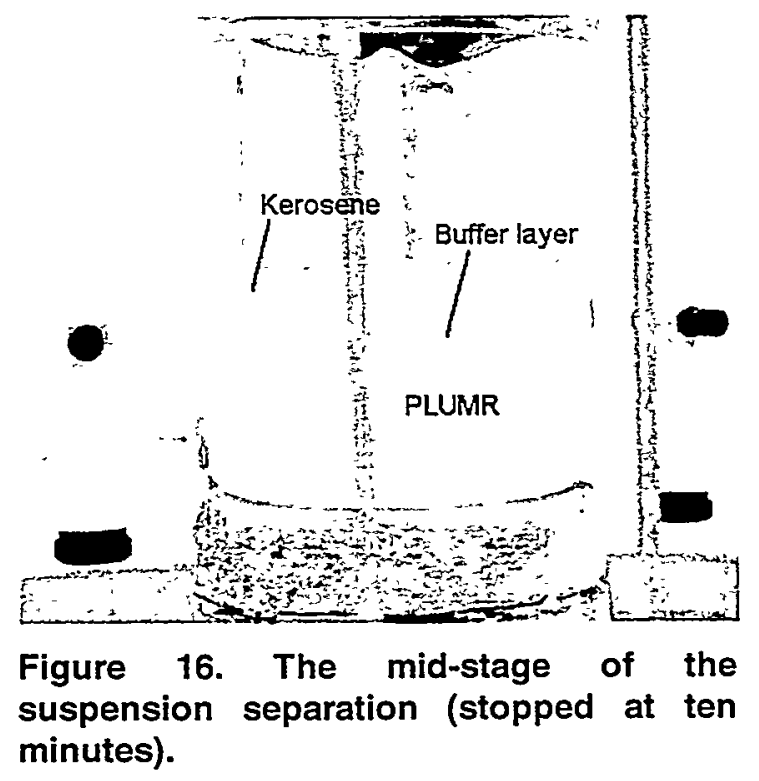




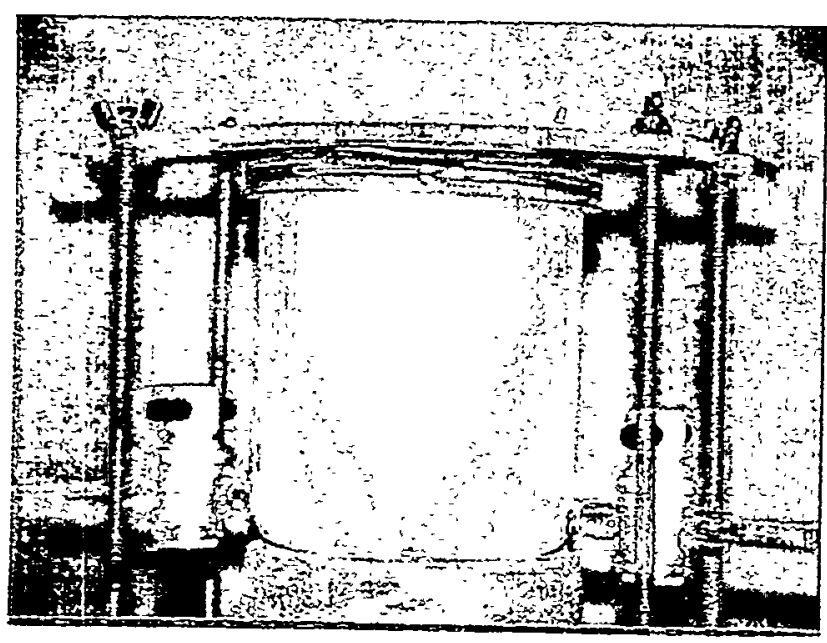

Figure 17. The mid-stage of the suspension separation (in rotating state at $300 \mathrm{rpm}$ ).

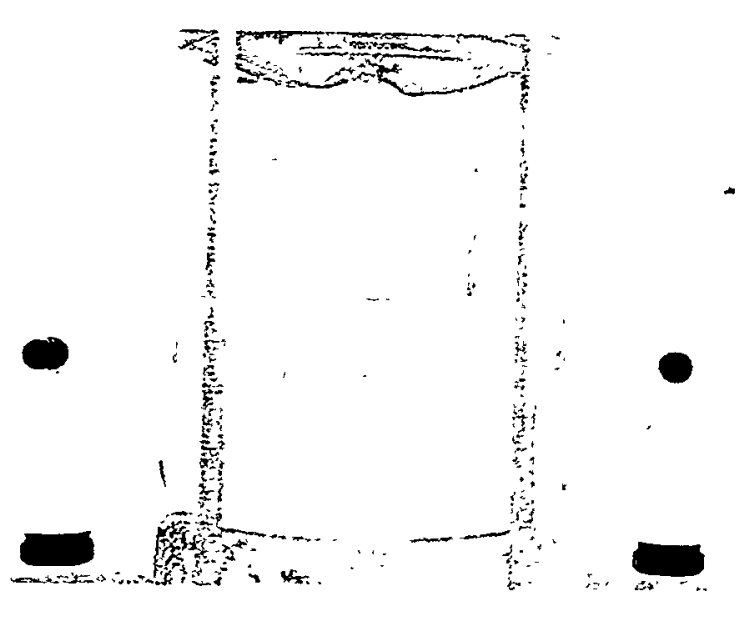

Figure 18. The final phase distribution of the suspension after rotation. 


\subsection{NUMERICAL MODELING OF METAL/GLASS PHASE SEPARATION}

\subsection{MATHEMATICAL MODEL AND NUMERICAL METHODS}

The state-of-the-art two-fluid model, which is implemented in the software package Fluent 4.3, has been used in this study. The modeling is based on the following assumptions: (1) a pressure field is shared by both the metal and glass phases; (2) momentum and continuity equations are solved for each phase; (3) the metal and glass are incompressible and have constant density and viscosity; (4) the glass is distributed in the liquid as spherical bubbles with uniform size. The governing equations are summarized below.

The continuity equation is expressed as:

$$
\nabla \cdot\left(\alpha_{p} \bar{U}_{p}\right)=0
$$

Where $\mathrm{p}$ refers to the metal $(\mathrm{m})$ or glass $(\mathrm{g})$ phase.

The momentum equation is:

$$
\begin{gathered}
\alpha_{p} \rho_{p} \frac{D \bar{U}_{p}}{D t}=\nabla \cdot \alpha_{p}\left[\mu_{p} \nabla \bar{U}_{p}-\rho_{p}\left(U_{p}^{\prime} U_{p}^{\prime}\right)\right]-\alpha_{p} \nabla p-\alpha_{p} \rho_{p} G+\mathrm{K}\left(\bar{U}_{p}-\bar{U}_{q}\right) \\
\mathrm{p}=\mathrm{m}, \quad \mathrm{g} \text { and } \mathrm{q}=\mathrm{m}, \quad \mathrm{g}(\mathrm{p}=\mathrm{q})
\end{gathered}
$$

Where $\mathrm{K}$ denotes the interphase momentum exchange coefficient and $\mathrm{G}$ represents gravity force.

The constitute equations for volume fractions can be expressed as follows:

$$
\begin{aligned}
& \alpha_{\mathrm{m}}+\alpha_{\mathrm{g}}=1 \\
& \nabla \cdot\left(\alpha_{\mathrm{g}} \overline{\mathrm{U}}_{\mathrm{g}}\right)=0
\end{aligned}
$$

Based on assumption 4, the exchange coefficient is determined by the following equation:

$$
\mathrm{K}=\frac{3}{4} C_{D} \alpha_{g} \frac{\rho_{m}\left|\bar{U}_{m}-\bar{U}_{g}\right|}{d}
$$

The drag coefficient, $\mathrm{CD}$, in Equation 5 is a function of the Reynolds number, Re:

$$
\begin{array}{cr}
C_{D}=\frac{24}{\operatorname{Re}\left(1+0.15 \operatorname{Re}^{0.687}\right)} \quad & \operatorname{Re} \leq 1000 \\
C_{D}=0.44 & \operatorname{Re}>1000
\end{array}
$$


Where

$$
\operatorname{Re}=\rho_{m} \frac{\left|\bar{U}_{m}-\bar{U}_{g}\right|}{\mu_{m}} d
$$

\subsection{PHASE DISTRIBUTION RESULTS}

In the numerical analysis, it is assumed that the glass is uniformly distributed in the metal phase as spherical droplets before separation. Four cases have been run with three glass content percentages-2\%,5\%, and 10\%-and two rotating speeds-300 rpm and $150 \mathrm{rpm}$. The results of the glass volume fraction distribution are presented in Figures 19 and 20.

In Figure 19, the right and left halves are the results of the cases with glass contents of $2 \%$ and $5 \%$, respectively, with the same rotating speed of $300 \mathrm{rpm}$. Figure 20 shows the results for the cases with $10 \%$ glass content and with rotating speeds of $150 \mathrm{rpm}$ and $300 \mathrm{rpm}$ on the right and left halves, respectively.

From the figures, it can be seen that, at the low glass content percentages ( $2 \%$ and $5 \%$ ), the glass phase cannot be separated from the metal phase and that the two phases are separated more clearly for the higher glass content percentage (10\%). Figure 20 shows that at the high glass content percentage, more glass phase locates in the center of the crucible at the higher rotating speed than for the lower rotating speed. This point implies that high speed cannot be applied for the DCS method; otherwise, the heavier phase may be pushed out first instead of the lighter phase by the plunger movement.
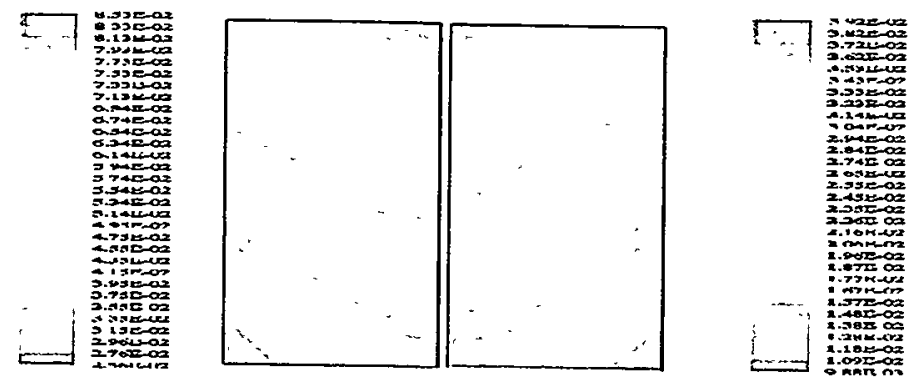

Figure 19. Glass volume fraction distribution for the cases of $2 \%$ (left) and $5 \%$ (right) glass content with a rotating speed of $300 \mathrm{rpm}$.
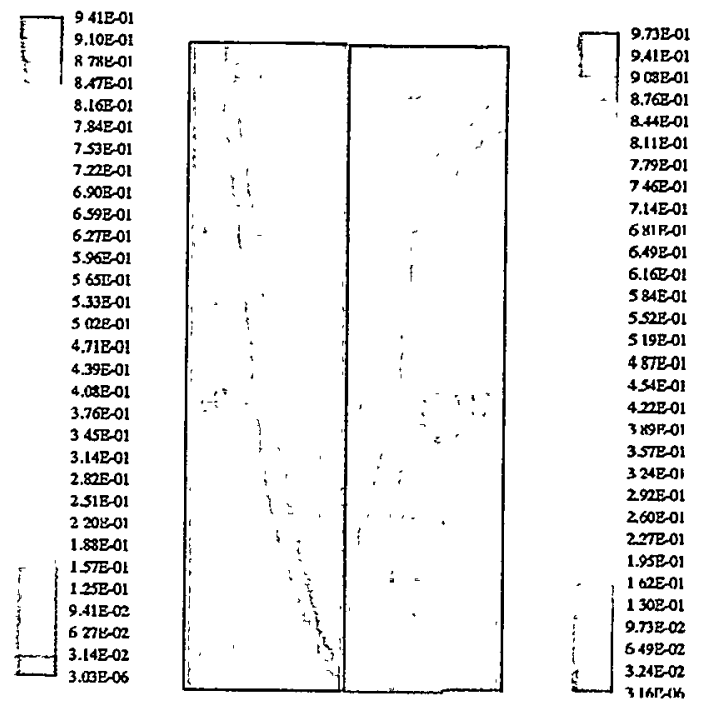

Figure 20. Glass volume fraction distribution for the case of $10 \%$ glass content with rotating speeds of $150 \mathrm{rpm}$ (left) and $300 \mathrm{rpm}$ (right). 


\subsection{MOLTEN METAL/GLASS PHASE SEPARATION EXPERIMENTS}

\subsection{MOLTEN METAL/GLASS PHASE SEPARATION TESTS}

The experimental setup for the molten stainless steel/glass phase separation includes an adjustable motor, a turntable, and a flange crucible fixture. The photos of the crucible assembly and system are shown in Figures 21 and 22.

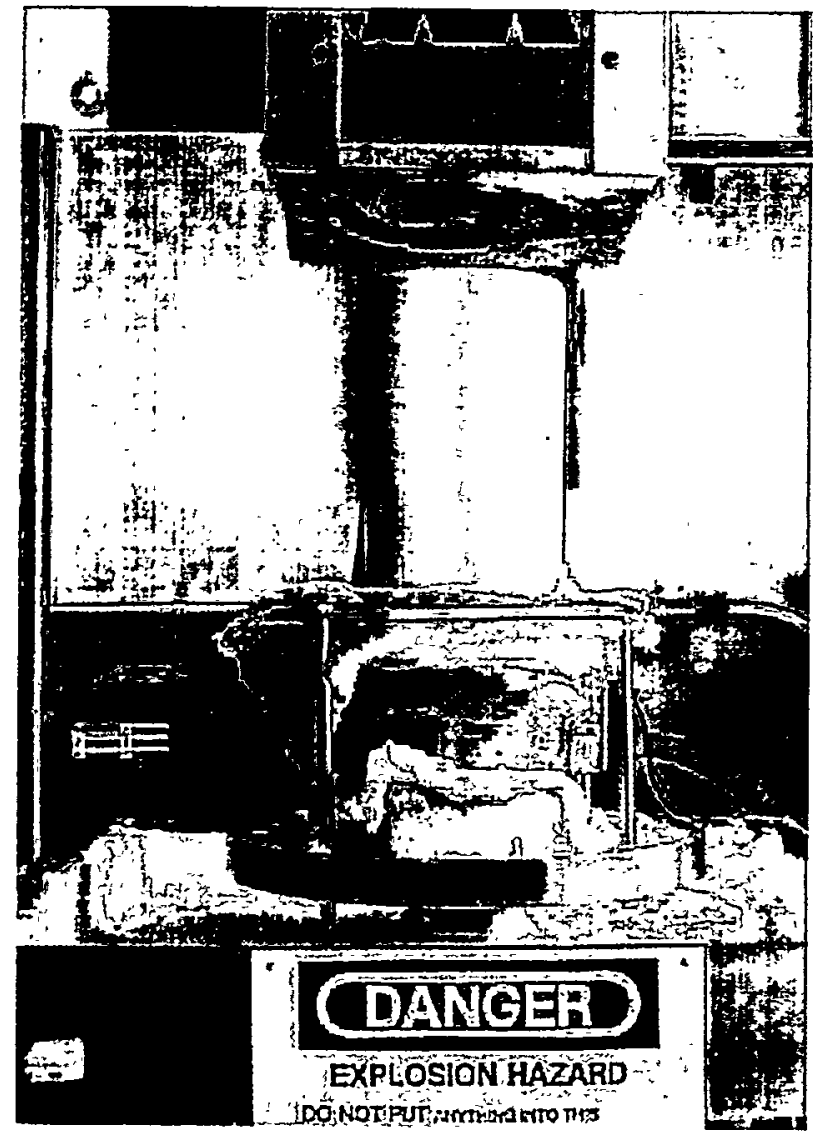

Figure 21. Flange crucible assembly.

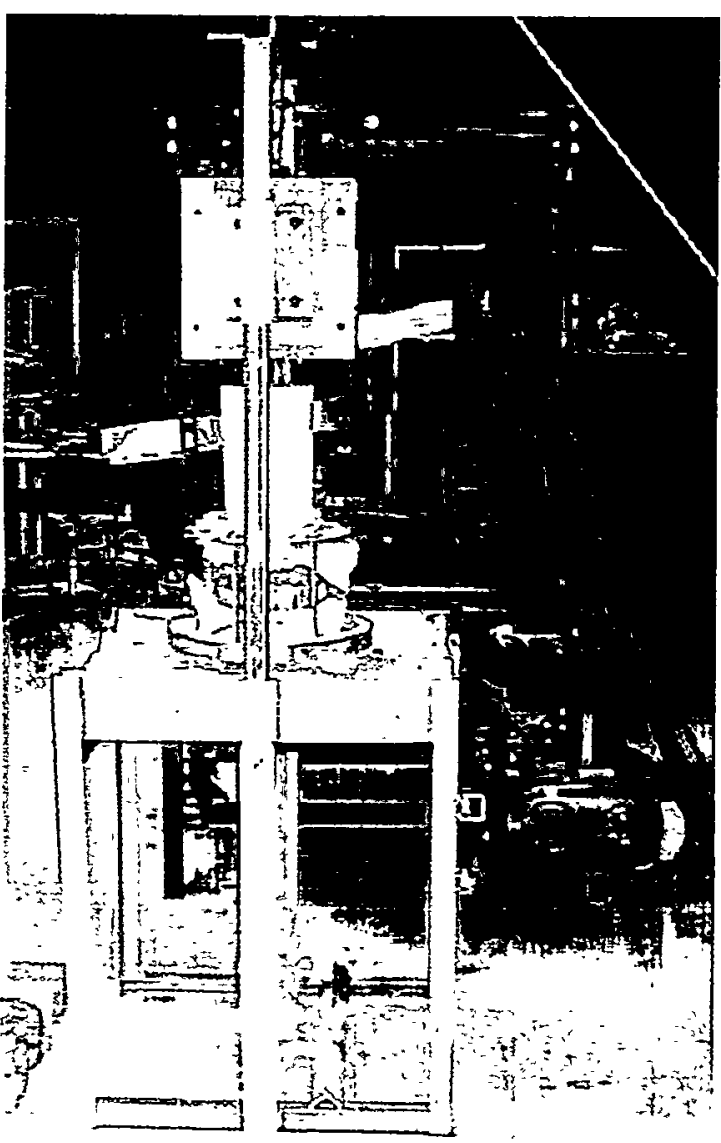

Figure 22. Molten metal/glass phase separation test setup. 
After initial setup testing, two kinds of tests of phase separation were conducted, solidification being performed in static crucible or in rotating crucible. In the tests, 316 stainless steel was selected as metal phase, and SRS waste glass and commercial glass mixture was used as glass phase. The tests indicated that by combining the two types of glass, the proper melting temperature and viscosity for the glass phase could be obtained. The molten mixture was solidified in static crucible and in rotating crucible, respectively.

For the static solidification, the temperature history of solidification in the metal phase and in the glass phase was measured. Figure 23 shows the temperature history at two locations along the center line within the metal and glass phases, respectively. $\mathrm{T} 1$ indicates the measuring point within the stainless steel, and T2 indicates the point within the glass.

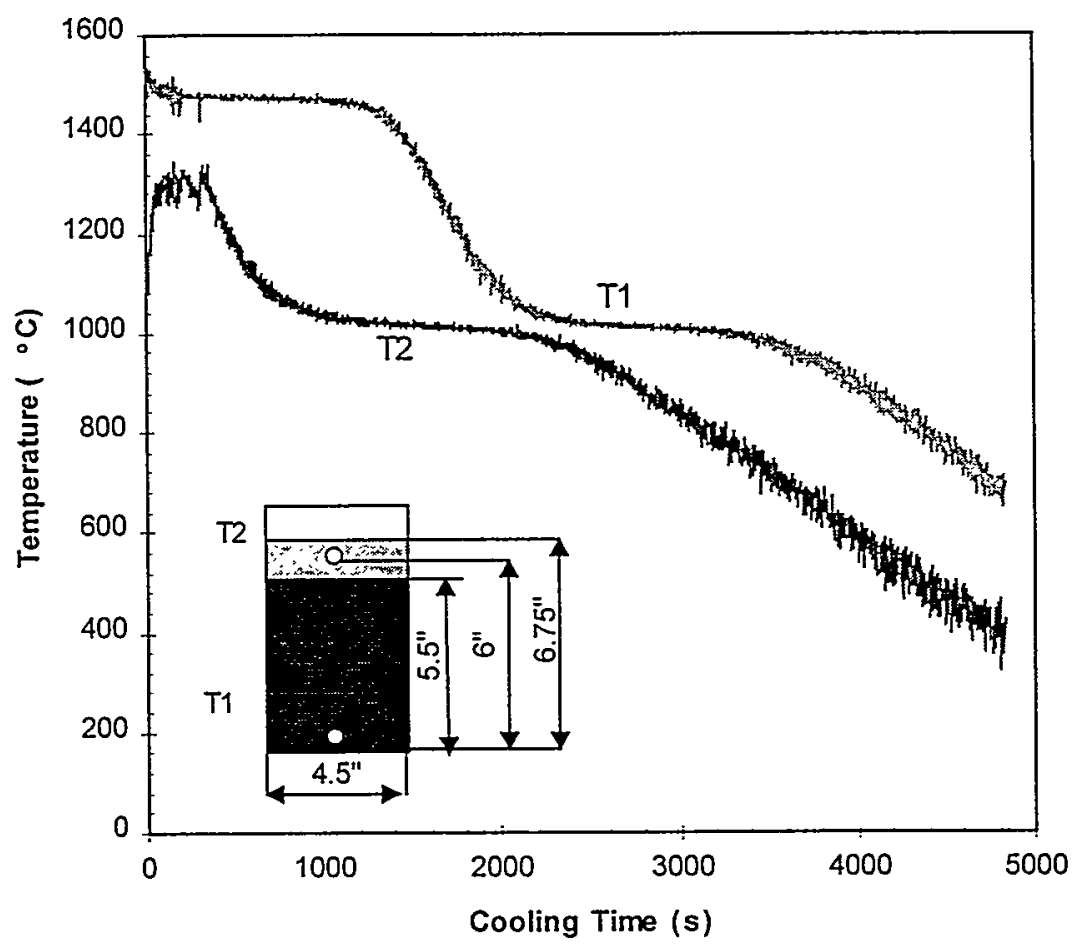

Figure 23. Temperature curves for two different locations during the stainless steel and mixed glass solidification test.

For rotating solidification, the rotation speed was $150 \mathrm{rpm}$. The final phase states are shown in Figure 24. Two distinguishable phases can be observed. After removing the glass phase, the metal phase ingot is shown in Figure 25. For both cases, a clear and clean top surface of metal ingot exists. 


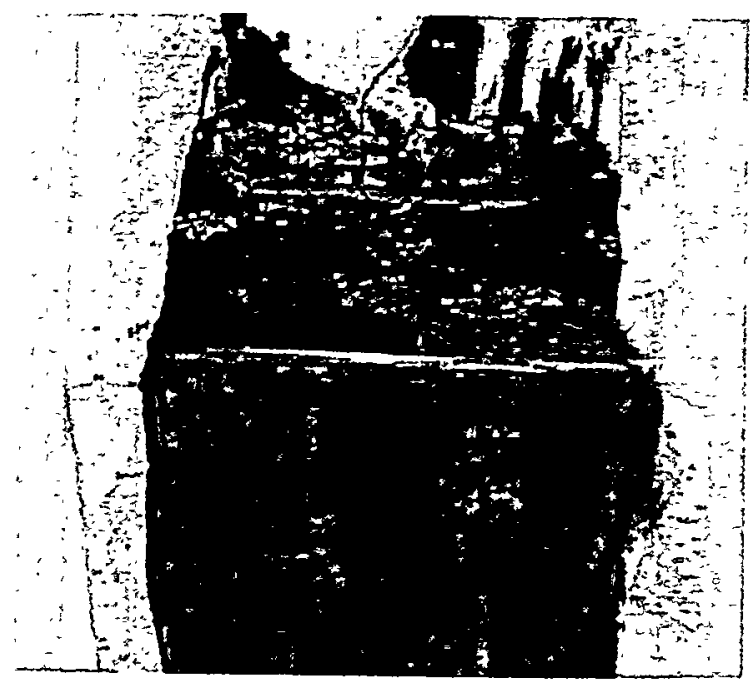

Figure 24. Final phase states after melting, rotating and solidification.

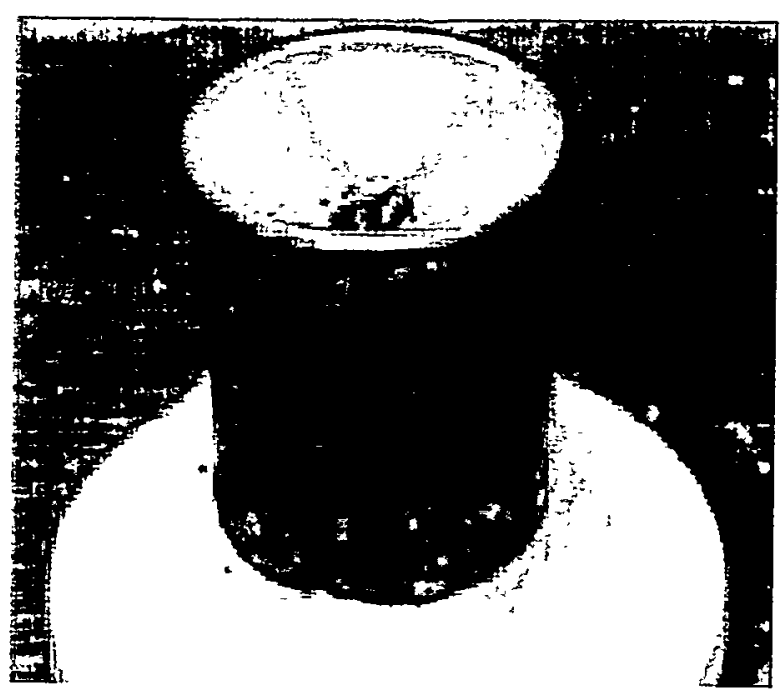

Figure 25. Metal phase ingot and the interface shape (150 rpm).

The interface shape for the rotating case was measured and plotted in Figure 26.

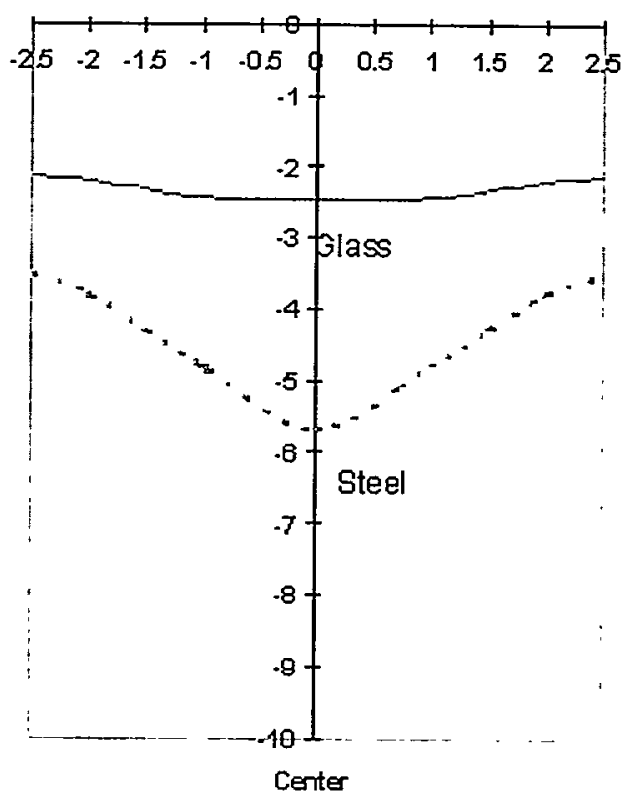

Figure 26. Free surface and interface shape. 


\subsection{STRUCTURE AND COMPOSITION ANALYSIS}

The structure and composition analysis was conducted on the samples from two kinds of ingots, one of them being solidified without rotating, another being solidified in a rotating crucible. Two samples sectioned from each ingot are shown in Figures 27 and 28.

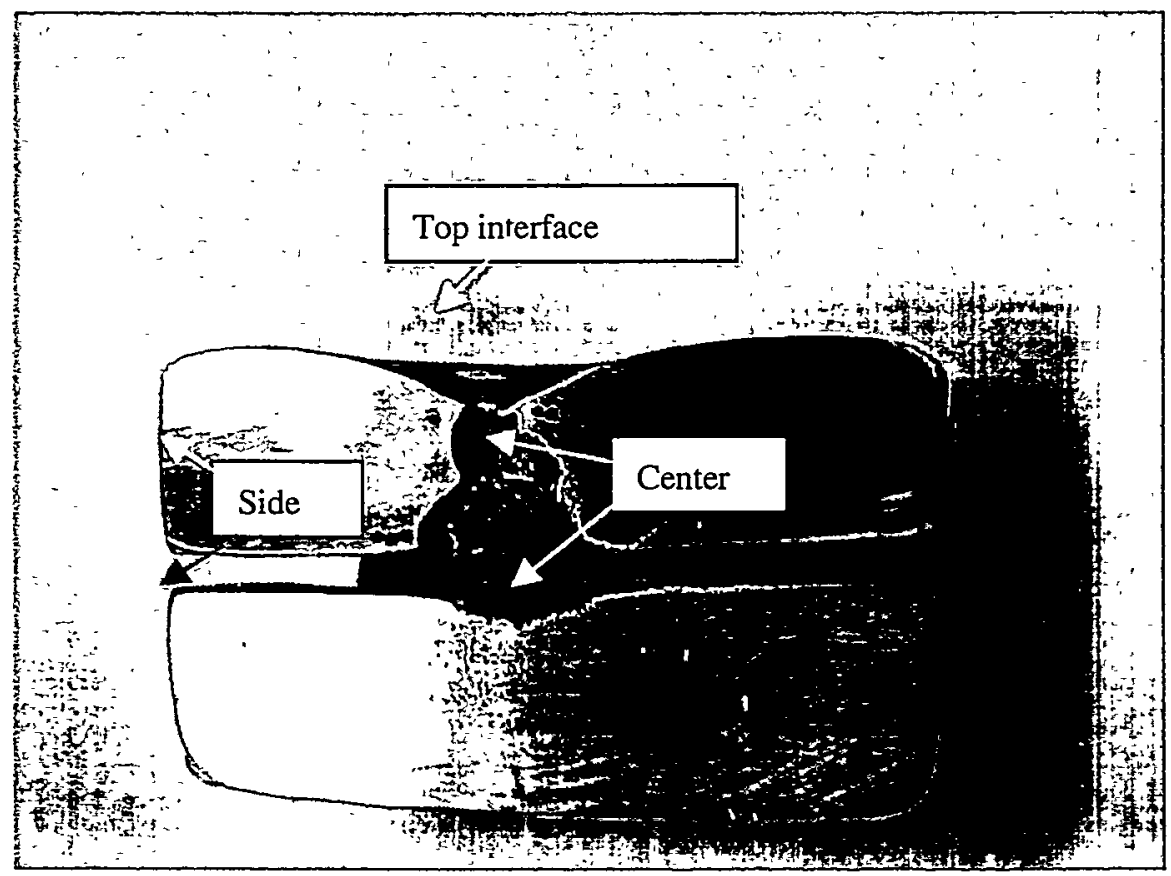

Figure 27. Samples from the ingot in static solidification.

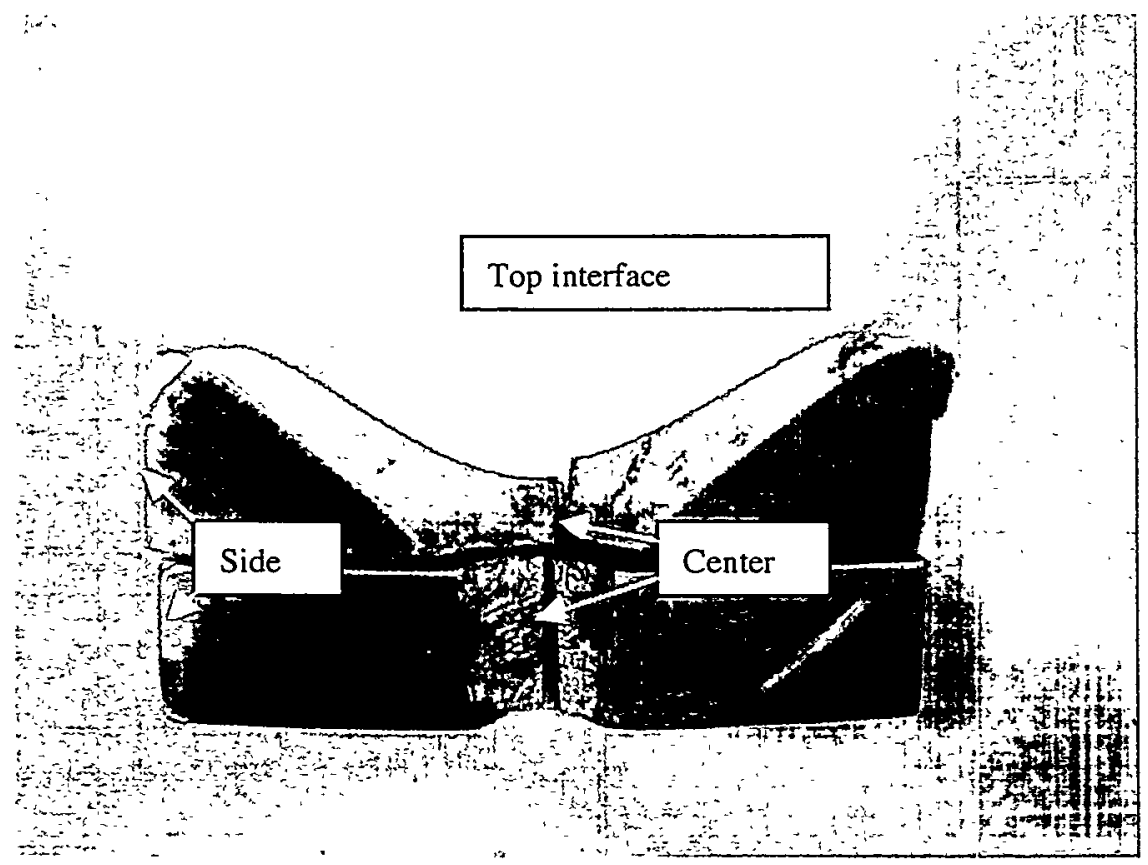

Figure 28. Samples from the ingot in rotating solidification. 
From Figure 27 and 28, it is can be seen that the ingot solidified in a rotating crucible has a clear interface of stainless and glass mixture, even at the center of the ingot, and has a dense structure from central area to side area of the ingot. But for static solidification, a lot of black things were captured in the metal. There is a loose zone in the center area of the ingot, and the interface of metal/glass mixture is very blurred, which means that glass mixture can't be separated clearly from metal phase, or purer metal can't be obtained in the static solidification case.

The microstructure and composition analysis was conducted on both samples using a Phillips XL30CP Scanning Electron Microscope with an EDAX-Ray Dispersive Sepectrometer. For composition analysis, the amount of glass present in the metal matrix was estimated by examining the relative concentration of elemental silicon in the specific area of interest because the main composition of glass mixture is $\mathrm{SiO}_{2}$. The lower silicon content means the higher cleanness of the ingot. The samples were imaged and their composition determined typically at $50 \mathrm{X}$ magnification at key area along the specimen. The image was carried out at a beam accelerating voltage of $15 \mathrm{Kev}$. The working distance and spot size was varied to produce a count rate of approximately 4000 counts/second. The samples could be analyzed without the necessity of coating them with a conductive coating. The results are shown in Figures 29 and 30.

From Figure 29, it can be seen that there are a lot of irregular parts distributed in the clean matrix (stainless steel). The silicon content of those irregular parts is $31 \mathrm{wt} \%$, which means those parts are pure glass mixture. The silicon content of the whole area is $9.0 \%$. But for the rotating solidification case (Figure 30), even in the central area of the ingot, such irregular parts as in Figure 29 can't be found. The whole ingot is stainless steel, and the silicon content is about $0.32 \sim 0.47 \%$, much lower than that of the ingot solidified in static crucible. The silicon content of the interface of the ingot is only $1.2 \%$.

From the above results, such a conclusion should be obtained: The centrifugal separation process is a useful and successful process in the separation of metal/glass, and more clean metal can be obtained by using this innovative process. 

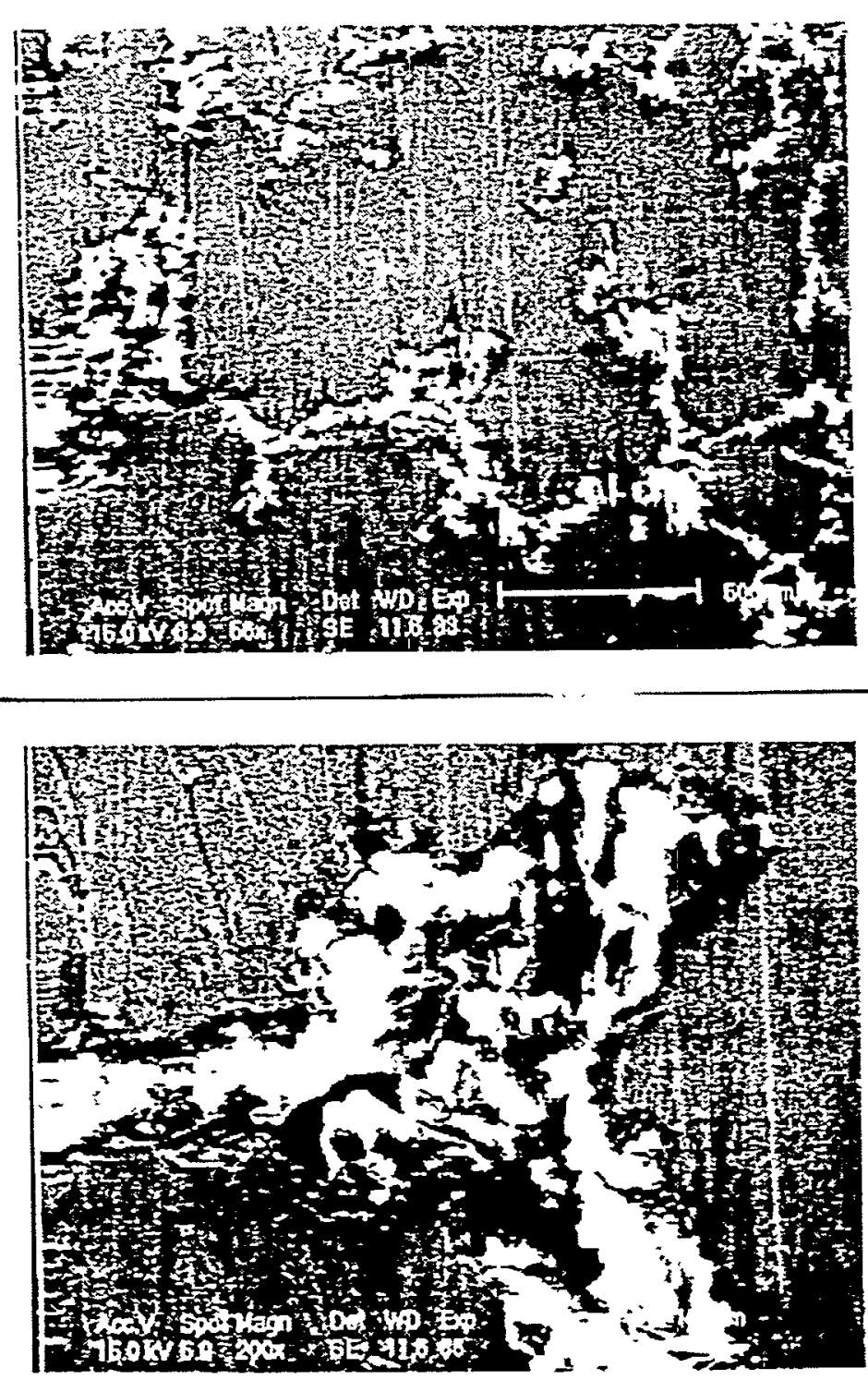

Figure 29. SEM analysis of the samples from the ingot in static solidification (near central area; irregular parts are glass mixture). 

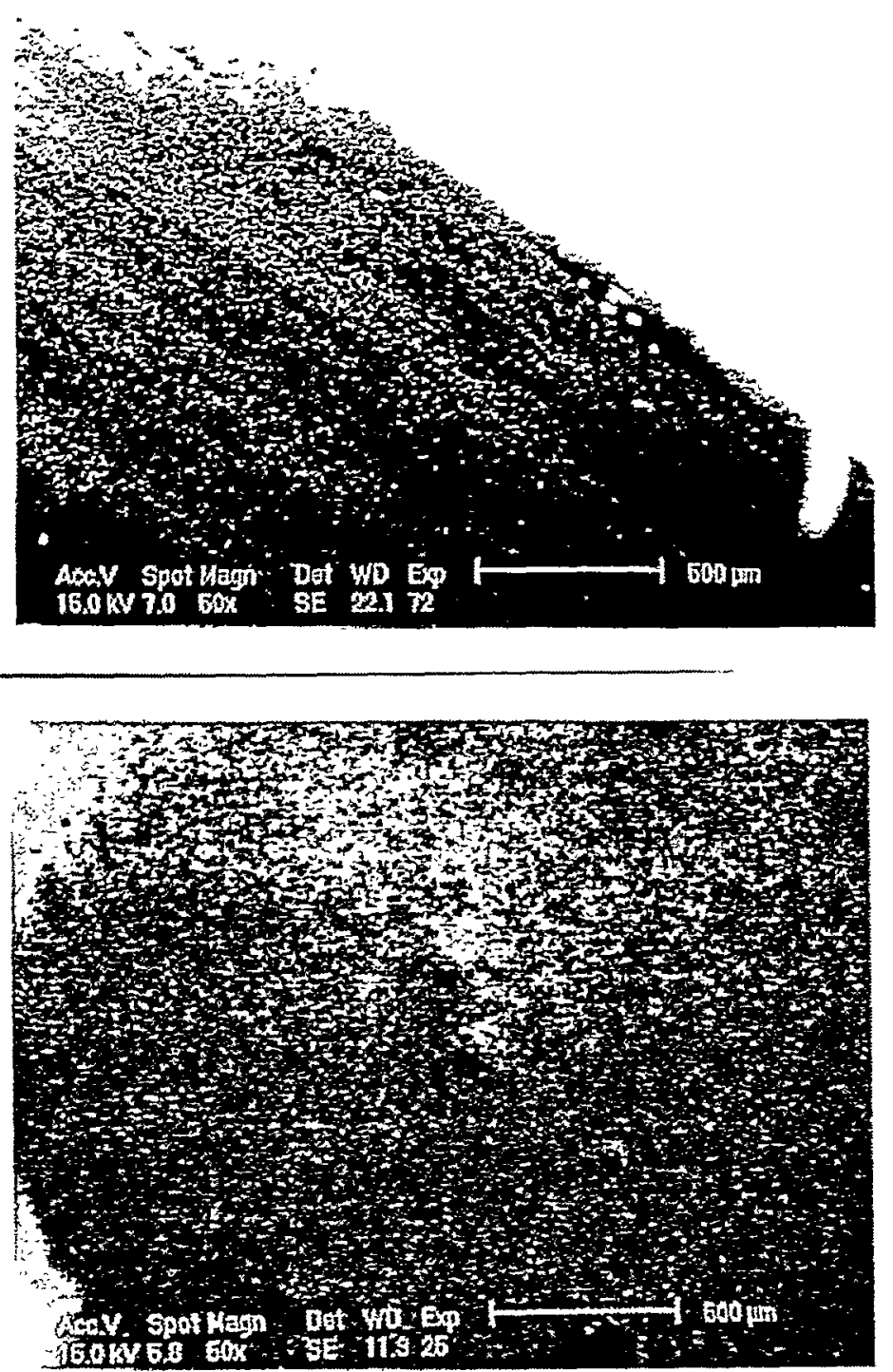

Figure 30. SEM analysis of the samples from the ingot in rotating solidification (Upper: near central area; Lower: near middle area; black points are contamination from outside). 


\subsection{CONTINUOUS SEPARATION DEMONSTRATION}

Based on simulation tests of liquid-liquid separation and molten metalglass phase separation experiments, a special separator and a continuous simulation test setup was designed, fabricated, and set up to demonstrate the operating principle and performances, which are shown in Figure 31 and Figure 32, respectively.

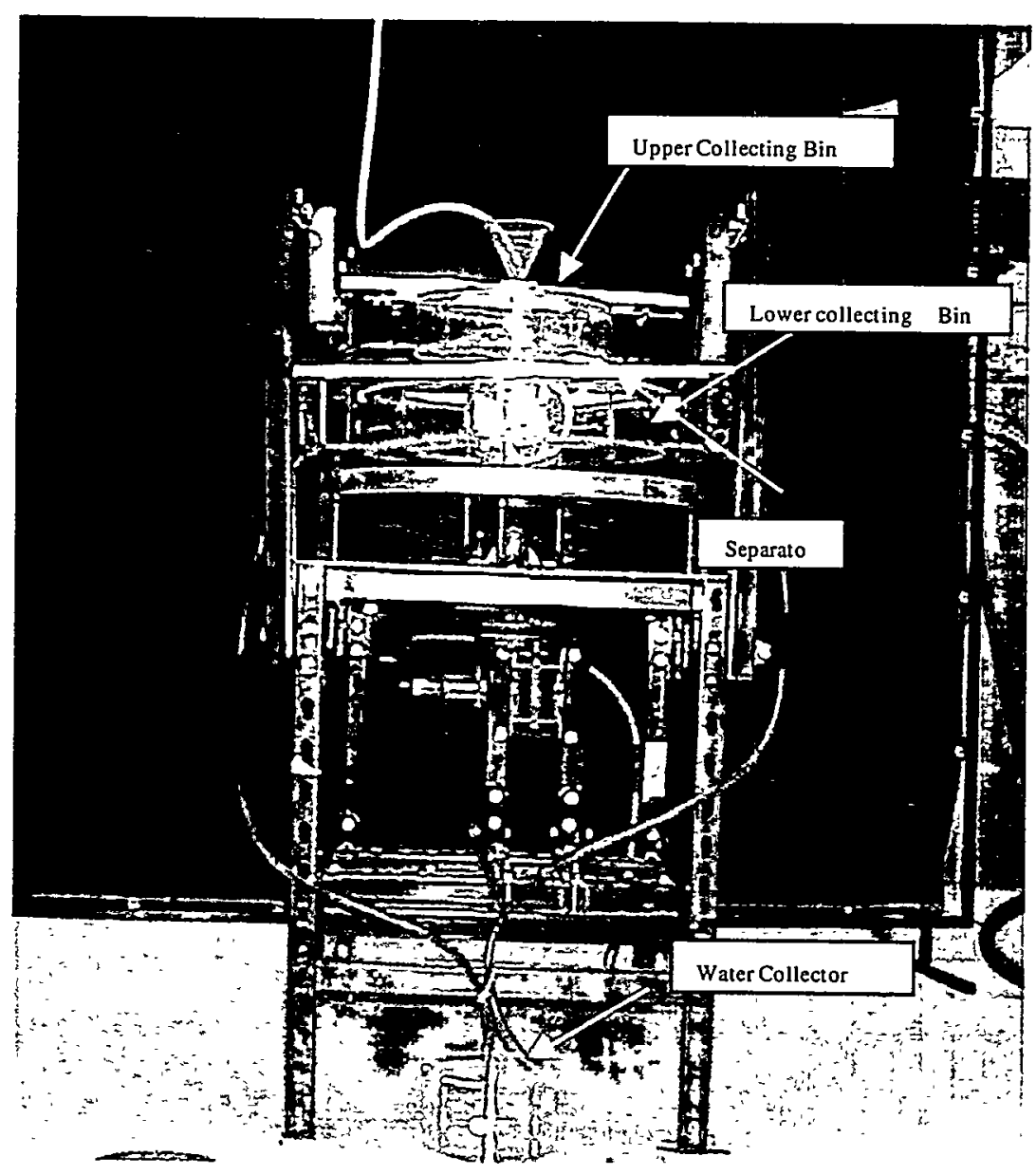

Figure 31. Continuous separation setup. 


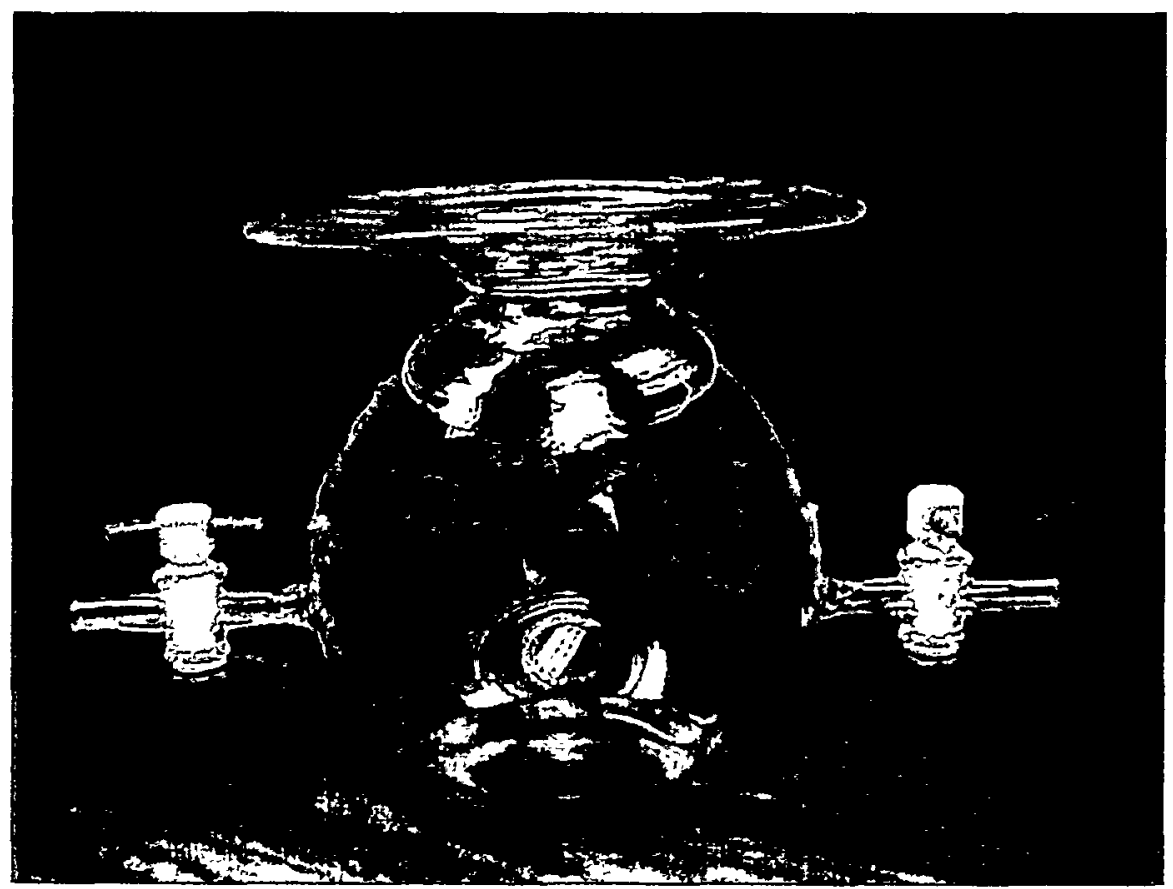

Figure 32. Separator.

In the simulation test, the mixture of simulating liquids (water and kerosene, which properties are shown in Table 1) is continuously added into the separator from the top during rotating. The mixture feed is separated under centrifugal force. Heavier liquid is pushed toward the middle side of the separator, continuously flowing out from the separator through valves on the middle side of the separator, and collected in a lower collecting bin, then flowing out. Lighter liquid (kerosene) is kept in the separator, and after the amount of the lighter liquid exceeds a limit, the liquid will continuously flow out of the neck of the separator along the upper inner wall of the separator, being "thrown away" and collected in an upper collecting bin, then flowing out. Figure 33 shows the separation in process, and Figure 34 shows the results of separation. At this point, a continuous separation process is achieved. From the result, clear continuous separation has been observed.

For the real case of separation of the mixture of glass and metals, the glass and metal are molten in a furnace (arc or conduction furnace) first, then continuously poured in a separation system like the simulation system above. The glass or slurry, which has lower density and contains much more radioactive substance, flows out of a rotating separator from the top and collects. The heavier liquid, the much purer molten metal flow out of the separator from a valve in the middle side of separator, can be cast in ingot form for reuse. 


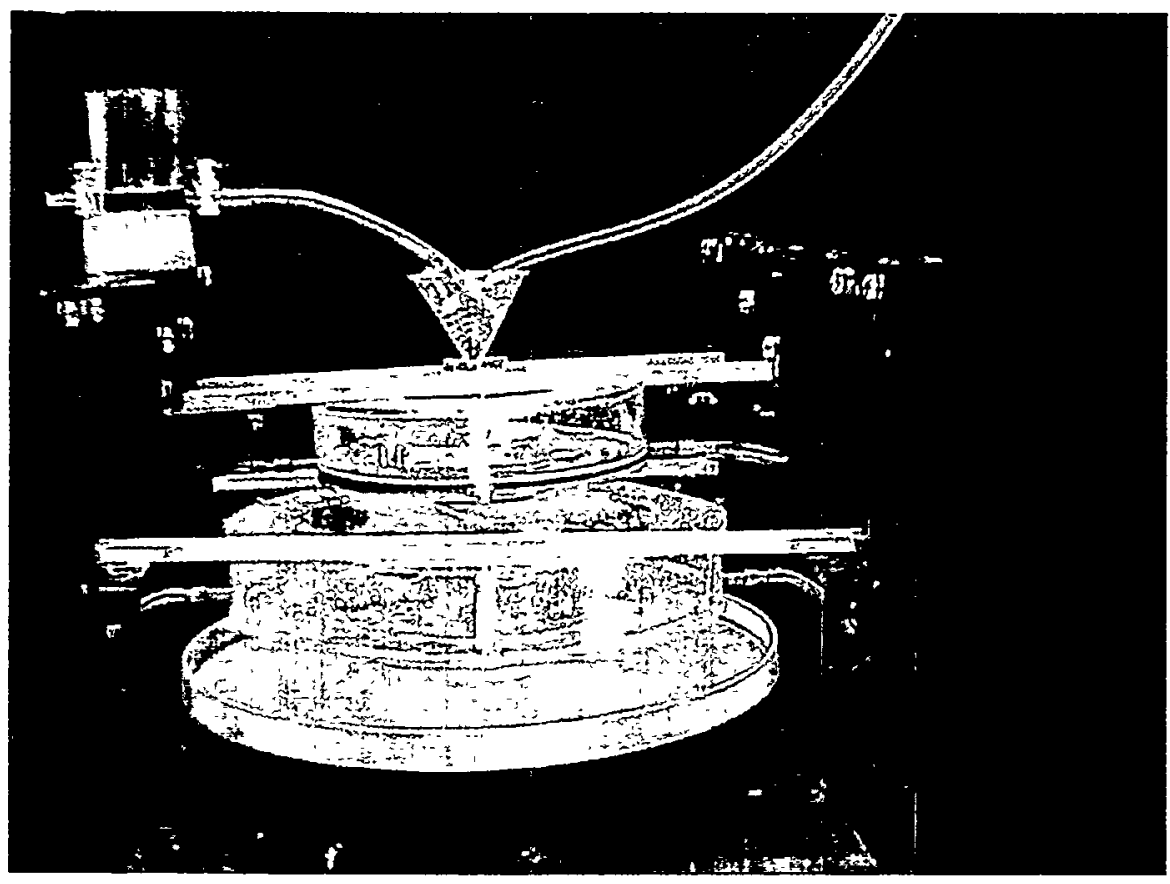

Figure 33. Separation in process.

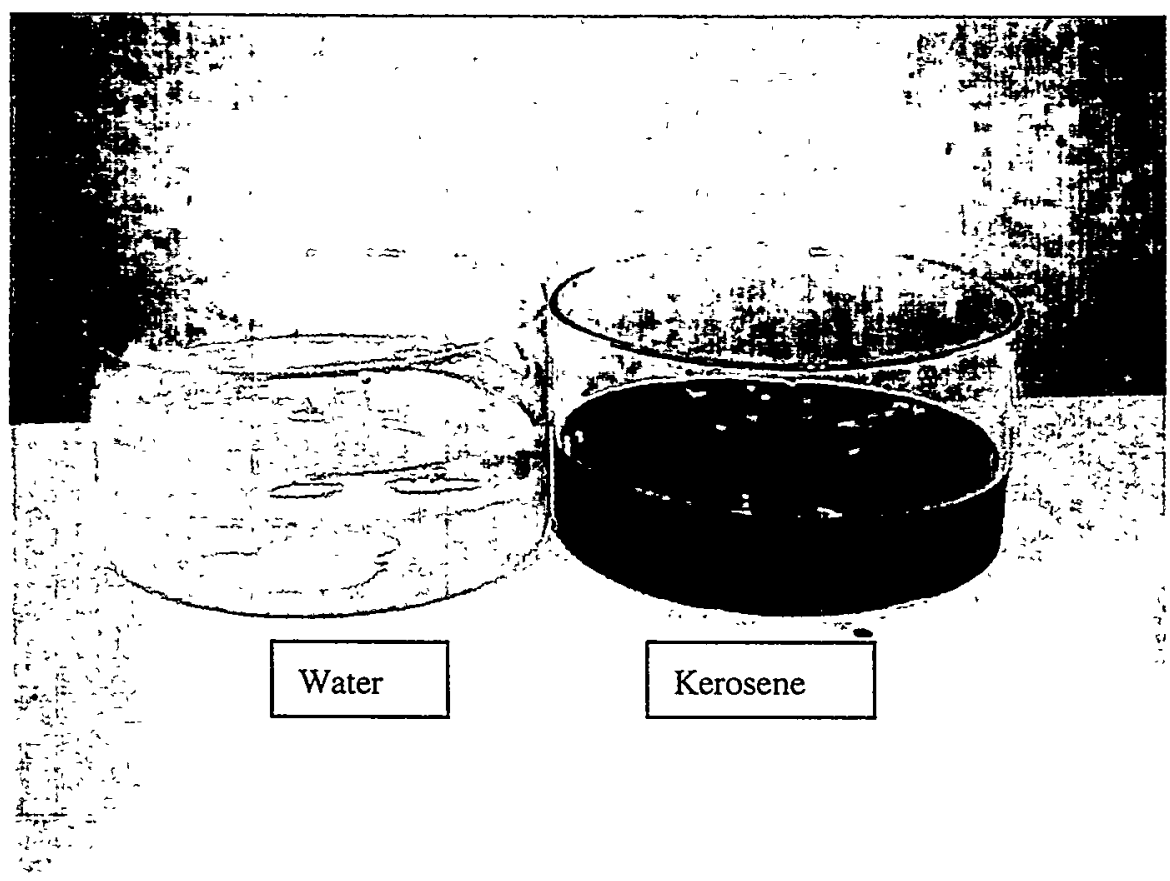

Figure 34. After separation. 
In addition, there is an essential need for efficient extraction/separation devices for the various kinds of DOE liquid waste treatment processes. These processes include solvent extraction of radionuclides from aqueous tank waste; extraction and recovery of uranium, transuranics, and fission products from acidic high-level waste; cleanup and recycling of oil and chemical spills in water resources; liquid-liquid chemical extraction processes; and de-watering organic liquids. The conventional vessel-type separators have several disadvantages, such as large volume, low efficiency, and high cost. They do not meet the special needs of nuclear waste separation, remediation, and recycling activities considering the possibility of recontamination and hazardous material exposure. Therefore, advanced separation apparatuses, featuring compact, effective, and in-line continuous operational modes, are desired for decontamination and decommissioning (D\&D) practices at DOE sites. Based on the simulation test results, an innovative liquid-liquid separator can be developed. 


\subsection{CONCLUDING REMARKS}

This project's completed tasks can be summarized in four phases-the melting and solidification experiments on metal, glass, and metal/glass mixtures; the simulation test of the separation process; the numerical modeling of metal solidification and phase separation; and the molten glass/metal phase distribution and separation. After examining the results, the following were noted:

1. The melting/solidification tests for stainless steel and aluminum have been conducted.

- The temperature history and distribution were measured during the solidification processes.

- The solidification rates were evaluated. The solidification rates for aluminum are faster than those for stainless steel.

- In the solidification tests, the temperature gradient was much higher along the central line than along the radius.

2. The melting/solidification tests for two kinds of borosilicate glass-commercial borosilicate glass and SRS waste glass-have been conducted.

- SRS glass has a much lower melting temperature and viscosity than the commercial borosilicate glass.

- The temperature history and distribution were measured in the solidification tests of glasses.

3. The simulation tests for the CS and the DCS technologies have been completed for four combinations of two immiscible liquids and a liquid suspension.

- The separation efficiency for the CS technology was measured. The results indicate that separation efficiency increases with the rotating speed when the rotating speed is lower than $300 \mathrm{rpm}$.

- During suspension separation, three liquid layers exist: a lower density liquid layer, a buffer layer (mixture), and a higher density liquid layer.

- The suspension separation demonstration also verified that centrifugal force can separate the glass inclusions from the molten metal phase.

4. Numerical studies have been conducted for molten iron and aluminum solidification and molten metal and glass phase separation in rotating crucibles.

- The solidification pattern, flow pattern, and temperature field were predicted and analyzed at different cooling conditions for iron and aluminum.

- The phase distribution results for phase separation modeling indicate that, at the lower glass content percentages ( $2 \%$ and $5 \%$ ), the glass phase cannot be clearly separated from the metal phase. The two phases separate more clearly for the high glass content percentage $(10 \%)$. 
- At the high glass content percentage, more glass phase locates in the center of the crucible at higher rotating speeds versus lower rotating speeds.

5. For the molten metal/glass phase separation experiments

- The solidification temperature history of the molten metal/glass was measured in glass and in metal at the same time.

- Several melting tests of stainless steel and glass mixtures have been conducted. The halfand-half mixture of the two kinds of glass has the proper melting point for melting with the stainless steel.

- The structure and composition analysis was conducted on the samples from two kinds of ingots in SEM.

- After solidification, the ingot has a clear interface between metal and glass mixture for rotating solidification (centrifugal separation), and the metal phase is clean and has much lower silicon content (lower glass content).

- For static solidification, the interface of metal/glass is blurred, a lot of glass mixture was captured in the metal matrix, and the silicon content is much higher than that for rotating solidification.

- The centrifugal separation is more efficient in the separation of metal/glass; more clean metal can be obtained.

6. For the continuous separation demonstration

- Continuous separation tests to demonstrate the operating principle and performances of the continuous separation of molten metal/glass were conducted successfully by using simulating liquids.

- Based on the simulation test results, an innovative liquid/liquid separation device can be developed. 


\subsection{REFERENCES}

Cotchen, J.K., and Davis, H.F., 1992. Electric Arc Furnace Processing of Solid Waste, presented at the International Symposium, Process of Residues and Effluents, TMS Annual Meeting.

Enokizono, M., Todaka, T., Yokoji, K., Wada, Y., and Matsumoto, I., May 1995, "ThreeDimensional Moving Simulation of Levitation-Melting Method," IEEE Transactions on Magnetics, Vol. 31, No. 3, Part 1, pp. 1870-1872.

Gillins, R.L., and Poling, S.D., May 1994, "Plasma Hearth Waste Treatment Demonstration for Radioactive Mixed Waste," International Incineration Conference Proceedings.

Grozhik, V. A., Bychko, G. V., and Khodskij, L. G., 1992, "Effect of Additives on Properties of Lead-Borosilicate Glasses and Thin-Film Coatings on their Basis," Steklo Keram, No. 2, pp. 25-27.

Gupta, R., Mauri, R., and Shinnar, R., 1996, "Liquid-Liquid Extraction Using the CompositionInduced Phase Separation Process," Ind. Eng. Chem. Res., Vol.35, pp.2360-2368.

Hassel, G.R., Geimer, R.M., Batdorf, J.A., and Leatherman, G.L., May 1994, "Evaluation of the Plasma Hearth Process for Mixed Waste Treatment Applications," International Incineration Conference Proceedings.

Idaho National Engineering and Environmental Laboratory (INEEL), 1994, "Plasma Hearth Process Technology Development Project," Fiscal Year 1994 Year-End Report, INEEL, Idaho Falls.

Kawamura, K. and Ohuchi, J., 1995, "Characterization of Highly Waste Loaded Glass for HLW," Materials Research Society Symposium Proceedings, Vol. 353, No. 1, pp. 87-93.

Lakomskii, V.V., Marinskii, G.S., Bogachenko, A.G., Medovar, B.I., Sysonov, A.M., Zagatnyi, L.S., and Dregolyunk, V.I., 1985, "Separation of the Slag-Metal Emulsion and Removal of Liquid Non-Metallic Inclusions From Metal in the Field of Centrifugal Forces," Problems Spetsial'noi Elektrometallurgii, Vol. 1, No. 2, pp. 15-19.

Nemec, L., 1994, "Analysis and Modelling of Glass Melting," Ceramics - Silikaty, Vol. 38, No. 1, pp. 45-58.

Nishioka, M., Hirai, S., and Yanagisawa, K., 1990, "Solidification of Glass Powder With Simulated High-Level Radioactive Waste During Hydrothermal Hot-Pressing," Journal of the American Ceramic Society, Vol. 73, pp. 317-22.

Office of Environmental Management and Technology Development, 1995, Mixed Waste Characterization, Treatment, and Disposal Focus Area, United States Department of Energy - Office of Environmental Management, DOE/EM-0252.

Office of Environmental Management and Technology Development, 1995, Technology Catalogue, United States Department of Energy - Office of Environmental Management. 
Purohit, A., Webster, S., and Johnson, A., 1995, "Plasma Hearth Process Slag Chemistry and Slag/Metal Processing," Mixed Waste Characterization, Treatment, and Disposal Focus Area, Office of Environmental Management and Technology Development, pp. 14-15.

Robatel Group, March/April 1993, Advanced Centrifuges for Solid-Liquid Separation and Liquid-Liquid Extraction, Filtration \& Separation, pp.104-106.

Scholze, H., 1991, Glass-Nature, Structure, and Properties, Springer-Verlag, New York.

Science Applications International Corporation (SAIC), 1994, Plasma Hearth Metal/Slag Separation Testing, ANL RFP No. 94-60ML-18.

Skrovankova, D., Bennerova, L., and Hlavac, J., 1993, "Vitrification of Simulated IntermediateLevel Waste from Nuclear Power Plants I. Melting Behavior and Properties of Selected Glasses," Ceramics - Silikaty, Vol. 37, No. 1, pp. 49-55.

Smith, P.A., Vienna, J.D., and Hrma, P., 1995, "Effects of Melting Reactions on LaboratoryScale Waste Vitrification," Journal of Materials Research, Vol. 10, No. 8, pp. 21372149.

Tomozawa, M. and Doremus, R.H., 1985, Treatise on Materials Science and Technology, Glass IV Vol. 26, Academic Press, Orlando, Florida.

Viskanta, R., 1994, "Review of Three-Dimensional Mathematical Modeling of Glass Melting," Journal of Non-Crystalline Solids, Vol. 177, Part 1, pp. 347-362.

Wang, C.Y. and Beckermann, C., 1994, "Multi-Scale/-Phase Modeling of Dendritic Alloy Solidification, Transport Phenomena in Solidification," American Society of Mechanical Engineers, Heat Transfer Division, Publication HTD Vol. 284, ASME, New York, pp. 75-95.

Warr, G.G., Zemb, T.N., and Drifford, M., 1990, "Liquid-Liquid Phase Separation in Cationic Micellar Solutions," J. Phys. Chem., Vol.94, pp. 3086-3092.

Winegard, W.C., and Cole, G.S., 1964, "Thermal Convection During Horizontal Solidification of Pure Metals and Alloys," Journal Institute of Metals, Vol.93, pp. 153-164.

Wolff, F., and Viskanta, R., 1988, "Solidification of a Pure Metal at a Vertical Wall in the Presence of Liquid Superheat," International Journal of Heat and Mass Transfer, Vol.14, pp. 245-253.

Wu, Y., and Lacroix, M., 1993, "Numerical Study of Melting of Scrap Metal," Numerical Heat Transfer: An International Journal of Computation and, Methodology; Part A: Applications, Vol. 24, No. 4, pp. 413-425.

Xin, R.C., Liu, Y.Z., Sundaram, K., Dong, Z.F., and Ebadian M.A., November 1997, "LiquidLiquid Centrifugal Separation for Molten Metal/Slag System - Simulation Test and Numerical Study,"X-Change 97, Miami, Florida. 